\title{
Neuroendocrine and metabolic components of dopamine agonist amelioration of metabolic syndrome in SHR rats
}

\author{
Michael Ezrokhi, Shuqin Luo, Yelena Trubitsyna and Anthony H Cincotta*
}

\begin{abstract}
Background: The hypertensive, pro-inflammatory, obese state is strongly coupled to peripheral and hepatic insulin resistance (in composite termed metabolic syndrome [MS]). Hepatic pro-inflammatory pathways have been demonstrated to initiate or exacerbate hepatic insulin resistance and contribute to fatty liver, a correlate of MS. Previous studies in seasonally obese animals have implicated an important role for circadian phase-dependent increases in hypothalamic dopaminergic tone in the maintenance of the lean, insulin sensitive condition. However, mechanisms driving this dopaminergic effect have not been fully delineated and the impact of such dopaminergic function upon the above mentioned parameters of MS, particularly upon key intra-hepatic regulators of liver inflammation and lipid and glucose metabolism have never been investigated.
\end{abstract}

Objective: This study therefore investigated the effects of timed daily administration of bromocriptine, a potent dopamine D2 receptor agonist, on a) ventromedial hypothalamic catecholamine activity, b) MS and c) hepatic protein levels of key regulators of liver inflammation and glucose and lipid metabolism in a non-seasonal model of MS - the hypertensive, obese SHR rat.

Methods: Sixteen week old SHR rats maintained on 14 hour daily photoperiods were treated daily for 16 days with bromocriptine (10 mg/kg, i.p.) or vehicle at 1 hour before light offset and, subsequent to blood pressure recordings on day 14, were then utilized for in vivo microdialysis of ventromedial hypothalamic catecholamine activity or sacrificed for the analyses of MS factors and regulators of hepatic metabolism. Normal Wistar rats served as wild-type controls for hypothalamic activity, body fat levels, and insulin sensitivity.

Results: Bromocriptine treatment significantly reduced ventromedial hypothalamic norepinephrine and serotonin levels to the normal range and systolic and diastolic blood pressures, retroperitoneal body fat level, plasma insulin and glucose levels and HOMA-IR relative to vehicle treated SHR controls. Such treatment also reduced plasma levels of C-reactive protein, leptin, and norepinephrine and increased that of plasma adiponectin significantly relative to SHR controls. Finally, bromocriptine treatment significantly reduced hepatic levels of several pro-inflammatory pathway proteins and of the master transcriptional activators of lipogenesis, gluconeogenesis, and free fatty acid oxidation versus control SHR rats.

Conclusion: These findings indicate that in SHR rats, timed daily dopamine agonist treatment improves hypothalamic and neuroendocrine pathologies associated with MS and such neuroendocrine events are coupled to a transformation of liver metabolism potentiating a reduction of elevated lipogenic and gluconeogenic capacity. This liver effect may be driven in part by concurrent reductions in hyperinsulinemia and sympathetic tone as well as by reductions in intra-hepatic inflammation.

Keywords: Neuroendocrine, Bromocriptine, Diabetes, Insulin resistance, Resetting

\footnotetext{
*Correspondence: Anthony_Cincotta@veroscience.com
}

VeroScience LLC, Tiverton, RI 02878, USA 


\section{Introduction}

Many vertebrate species in the wild exhibit annual cycles of metabolism, oscillating between seasons of obese, insulin resistance and lean, insulin sensitivity (reviewed in $[1,2]$. The ability to anticipate a season of low food availability by the endogenous induction of the obese, insulin resistant state supports survival during such a subsequent season when food availability is scarce. During the obese, insulin resistant season, in the absence of ample carbohydrate in the environment, increased hepatic glucose output supports brain function while fat stores are utilized in insulin resistant peripheral tissues thereby sparing plasma glucose for utilization by the brain, which has a near absolute requirement for glucose as a fuel. The circadian rhythm of dopamine release at the region of the biological clock, the hypothalamic suprachiasmatic nuclei (SCN), has been implicated in the regulation of peripheral insulin sensitivity and glucose and lipid metabolism in such seasonal mammals (reviewed in [1,2]). The circadian peak of dopamine release at the region of the $\mathrm{SCN}$ in seasonal insulin sensitive animals is absent in seasonal insulin resistant animals [3] and ablation of this dopaminergic activity by $\mathrm{SCN}$ area site-specific neurotoxin application in seasonal or nonseasonal insulin sensitive animals induces a marked insulin resistant state [4]. Moreover, intraperitoneal or intracerebroventricular administration of bromocriptine, a potent dopamine D2 receptor agonist, to seasonal insulin resistant animals reverses the insulin resistance/glucose intolerance [5-7]. Such bromocriptine treatment has been demonstrated to reduce both hepatic glucose and lipid production and secretion in seasonal insulin resistant animals [6,8-10]. Other studies have identified the ventromedial hypothalamus as an additional target for such metabolic influences of hypothalamic dopaminergic activity (potentially in concert with or resulting from such activity at the region of the SCN). Bromocriptine treatment of seasonal animals reduces elevated ventromedial hypothalamus (VMH) norepinephrine (NE) and serotonin (S) neuronal activities [2] that are characteristic of the insulin resistant state across a variety of animal models of the condition [1] and that can induce the obese, insulin resistant condition in normal animals (via $\mathrm{VMH}$ $\mathrm{NE}$ and $\mathrm{S}$ infusion) through their regulation of the neuroendocrine axis (e.g., simultaneous increase in sympathetic tone, plasma insulin, glucagon and norepinephrine among other factors) without alteration of the diet $[1,11,12]$.

However, we are still searching for insights into how these (hypothalamic or other) influences of bromocriptine affect regulatory biochemical pathways in liver that facilitate/mediate these simultaneous bromocriptine effects on glucose and lipid metabolism therein and systemically. Also, it is not known whether such bromocriptine effects on VMH neurochemistry are specific to seasonal animals or are a fundamental-general phenomenon of the insulin resistant state among mammals, across seasonal and non-seasonal animal models of insulin resistance alike. Moreover, the potential impact of bromocriptine treatment not merely on insulin resistance but rather upon the MS (insulin resistance, obesity, dyslipidemia, hypertension, and hepatic inflammation) has not been fully investigated. This study therefore investigated the impact of bromocriptine treatment in the hypertensive, insulin resistant SHR rat on a) VMH neurochemistry known to regulate peripheral (hepatic) glucose and lipid metabolism, b) the broader malaise of MS (hypertension, obesity, fatty liver, hyperinsulinemia, insulin resistance, and proinflammatory state) that contribute to cardiometabolic risk and c) liver biochemical pathways operative in the (dys)regulation of hepatic glucose and lipid production, namely transcription factor or enzyme proteins modulating proinflammatory (SOCS3, NFKB, IKK, JNK), gluconeogenic (FOXO1-Ser256, PEPCK, G6Pase, PGC-1 $\alpha$ ) fatty acid oxidative (PGC-1 $\alpha$, PPAR $\alpha$ ), and lipogenic (SREBP-1, mTORC, PGC-1 $\beta$, PPAR $\gamma$ ) activities. Here we show that dopamine agonist treatment with bromocriptine at the onset of locomotor activity in SHR rats normalizes elevated levels of $\mathrm{VMH}$ noradrenergic and serotonergic activities associated with and known to induce insulin resistance and fattening in seasonal rodents. Such treatment also reduces hypertension, insulin resistance, fatty liver and several key hepatic transcription factors that induce hepatic pro-inflammatory pathways, gluconeogenesis and lipogenesis. The bromocriptine-induced reduction in hypertension is associated with and may be potentiated by its induced changes in $\mathrm{VMH}$ activity and reduced sympathetic tone. The bromocriptine-induced reduction in liver and adipose fat content is associated with and may derive in part from reductions of hyperinsulinemia, liver lipogenic responsiveness to insulin and pro-inflammatory pathways that potentiate lipogenic activity. The reduction in bromocriptineinduced insulin resistance is coupled to and may derive in part from reductions in hepatic transcription factors potentiating gluconeogenesis and fatty acid oxidation.

\section{Materials and methods \\ Animals}

Male spontaneously hypertensive rats (SHR) and Wistar rats (Taconic, Hudson, NY) were housed individually and habituated to our climate-controlled animal care facility (14 hour daily photoperiods, light onset at 05:00) for at least 14 days before initiation of any experimentation. They were allowed to feed (Standard lab chow $18.6 \%$ protein, $44.2 \%$ carbohydrate, and $6.2 \%$ fat rodent diet 2018, Harlan, NY) and drink ad libitum throughout the study period. At the initiation of experimentation, animals were 16 weeks of age and at an average body weight 
of $334 \pm 4$ grams. Male SHR rats of this strain and age are severely hypertensive [13].

\section{Experimental design}

Two separate investigations were conducted in this study. In the initial investigation, we tested for possible differences between hypertensive SHR versus normal Wistar rats in extracellular monoamine (dopamine, serotonin, and norepinephrine) metabolites (measure of neurotransmitter release level) in the VMH that are known to be strongly involved in the regulation of insulin sensitivity, liver glucose output, plasma lipid level and body fat store level in rodents $[1,11,12,14]$. This investigation also examined the potential impact of chronic bromocriptine administration upon these VMH monoamine profiles in SHR rats. In vivo microdialysis was employed to study daily extracellular profiles of monoamine metabolites in the $\mathrm{VMH}$ of SHRs treated with bromocriptine $(10 \mathrm{mg} / \mathrm{kg} /$ day $)$ $(\mathrm{N}=8)$ or vehicle $(\mathrm{N}=8)$ and vehicle treated, age-matched normotensive Wistar rats $(\mathrm{N}=6)$ (administered at 13 hours after light onset [HALO]) for 14 days. Microdialysis samples from the $\mathrm{VMH}$ of free living rats held under a daily photoperiod and allowed to feed and drink ad libitum during the sampling were collected every 2 hours continuously over a 24 hour period. Microdialysis samples were assayed via HPLC for the metabolites of dopamine (homovanillic acid, HVA), serotonin (5-hydroxy-indoleacetic acid, 5HIAA), and norepinephrine (3-methoxy-4-hydroxyphenylglycol, MHPG) as previously described [14].

In the second investigation, SHR rats were randomized to one of two treatment groups: bromocriptine $(10 \mathrm{mg} /$ $\mathrm{kg} /$ day) $(\mathrm{N}=8)$ or vehicle (30\% ethanol, USP) $(\mathrm{N}=8)$ administered intraperitoneally at 13 HALO (a time of peak dopamine release at the area of the SCN clock in nocturnal rodents [4]) daily for 16 days. A group of Wistar rats served as the wild-type control for lipid, insulin resistance, and blood pressure measures. Measurements of blood pressure were taken at 4 hours after light onset on the day before treatment initiation and again 14 days after treatment (15 hours after the final bromocriptine injection). Animals were sacrificed on day 16 of the study at 4 HALO, the peak time of daily fasting in these nocturnal animals, and blood samples were collected for analyses of humoral metabolic and immune factors, including plasma insulin, glucose, leptin, adiponectin, norepinephrine, and $\mathrm{C}$-reactive protein (CRP). Retroperitoneal fat pads were removed and weighed as an index of body fat store level and livers were quickly removed and frozen for quantitative analyses of proteins regulating inflammation ([nuclear factor kappa-light-chain-enhancer of activated B cells; NfkB], [IкB kinase; IKK $\alpha \beta$ ], [c-Jun N-terminal kinase; JNK], [suppressor of cytokine signaling; SOCS3]), gluconeogenesis ([peroxisome proliferator-activated receptor gamma coactivator-1 $\alpha$; PGC1 $\alpha$ ], [Forkhead box protein O1;
FOXO1], [Glucose 6-phosphatase; G6Pase], [Phosphoenolpyruvate carboxykinase; PEPCK]), lipogenesis ([peroxisome proliferator-activated receptor gamma coactivator-1 beta; PGC1 $\beta$ ], [sterol regulatory element-binding protein 1; SREBP1], [mammalian target of rapamycin complex 1; mTORC1], [peroxisome proliferator-activated receptor; PPAR $\gamma]$ ), and fatty acid oxidation (PGC1 $\alpha$ and PPAR $\alpha$ ), and for Total liver lipid content. Daily food consumption and body weight changes were monitored periodically over the course of the study. All animal experiments were conducted according to the protocols approved by the Institutional Animal Care and Use Committee of VeroScience, LLC.

\section{Blood pressure (BP) measurements}

Systolic and diastolic blood pressure was measured on conscious animals with a tail-cuff Volume Pressure Recording method (CODA-6 non-invasive blood pressure system, Kent Scientific Corp. Torrington, CT) following manufacturer's instructions. Several days before experimental recordings, rats were acclimated to the restraining cage and the tail cuff to minimize or reduce any stress influence on the readings. BP measurements were performed before and after 14 days of treatment. BP values per animal were the result of an average of 6-8 measurements.

\section{Surgery}

After a two week adaptation to the facility, each rat in the microdialysis study was anesthetized with a mixture of ketamine and xylazine (80:60 mg/kg body weight, i.p.) and placed on a stereotaxic apparatus (David Kopf). A 30gauge stainless steel guide cannula (Carnegie Medicine, Stockholm, Sweden) was permanently implanted aimed at the top of the VMH [15] at coordinates: $2.8 \mathrm{~mm}$ posterior to bregma, $0.7 \mathrm{~mm}$ right lateral to the midsagittal suture, and $9.0 \mathrm{~mm}$ ventral to the surface of the dura with the incisor bar set $1 \mathrm{~mm}$ below the interaural line. The cannula was secured permanently to the skull with three stainless steel screws penetrating the skull and acrylic cement.

\section{Microdialysis}

During the entire microdialysis procedure, each animal was placed in an acrylic bowl with free access to food and water and was maintained on a 14-h daily photoperiod (light onset 05:00 am). A 32-gauge dialysis probe with a 1-mm-long tip of semi-permeable membrane (20,000 molecular weight cutoff) was inserted into the guide cannula and the probe membrane was placed in the VMH at $9.0-10.0 \mathrm{~mm}$ with respect to the dura. Using a microinjection pump (Carnegie Medicine, CMA/100), filtered Ringer's solution (147 mM NaCl, $3.4 \mathrm{mM}$ $\mathrm{CaCl}_{2}, 4.0 \mathrm{mM} \mathrm{KCl}, \mathrm{pH} 6.0$ ) was continuously perfused through the probe at a rate of $0.12 \mu \mathrm{l} / \mathrm{min}$. The probe was connected to the microinjection pump by microbore Teflon tubing through a counterbalanced 2-channel liquid swivel arm (Bioanalytical Systems, West Lafayette, IN) attached to the 
rim of the bowl, thus permitting the animal to move freely without the tubing becoming tangled during the experimental period. Rats were put in the bowl and attached to the microdialysis device at 10:00 hours (5 HALO) on the test day following 16 days of treatment and sample collection subsequently began at 5 hours after light onset. Microdialysis samples were collected into $300 \mu \mathrm{l}$ vials (containing $2 \mu \mathrm{l}$ of $0.1 \mathrm{~N}$ perchloric acid solution) at 2hour intervals continuously for 24 hours through an automated refrigerated fraction collector (modified CMA/170, CMA/Microdialysis, Acton, MA, USA). Bromocriptine or vehicle was given 1 hour before light offset daily for 14 days including on the day of microdialysis.

\section{Analysis of microdialysis samples}

The dialysis samples were analyzed by high-performance liquid chromatography with electrochemical detection (HPLC-EC with radial-flow cell; Bioanalytical System BAS 200). A $5 \mu$ dialysate sample was injected into the system by an autosampler (Bioanalytical System Sample sentinel). The column used was a $100 \times 2 \mathrm{~mm}$ reverse phase Octadecyl-silica ODS with $3 \mu \mathrm{m}$ particle packing (BAS Unijet LC Column). The mobile phase contained $0.1 \mathrm{M}$ monochloroacetic acid, $1.0 \mathrm{mM}$ sodium octyl sulfate, $0.7 \mathrm{mM}$ EDTA, $10 \mathrm{mM} \mathrm{NaCl}$, and $2 \%$ (v/v) acetonitrile, adjusted to $\mathrm{pH}$ 3.1. The mobile phase was filtered and degassed before use, and delivered at a flow rate of $400 \mu \mathrm{l} / \mathrm{min}$. A glassy carbon detector electrode (UniJet ${ }^{\mathrm{mm}}$ Amperometric Detector; BAS) was used for detection with an electrode oxidation potential of $0.65 \mathrm{~V}$. Detector output was recorded on a computer. Peak integration and quantitation were performed via computerized software using an external standard for calibration. Standards were prepared in $0.1 \mathrm{~N}$ perchloric acid. Each of 5-HIAA, MHPG and HVA contents in the dialysate were determined. Results are reported as pg amine metabolite per $5 \mu \mathrm{l}$ of dialysate.

Assay of blood samples and analysis of liver lipid content Blood glucose concentrations were determined by a blood glucose monitor (OneTouch Ultra, LifeScan, Inc, Milpitas, California). Plasma insulin, leptin, adiponectin, norepinephrine, and C-reactive protein (CRP) were assayed by EIA using commercially available assay kits utilizing anti-rat serum and rat insulin, leptin adiponectin, and CRP as standards (ALPCO Diagnostics, Salem, NH). Liver tissue was homogenized in 5\% NP-40, heated, centrifuged, and supernatant assayed for triglyceride content by Triglyceride Determination Kit (Sigma-Aldrich, St. Louis, MO).

\section{Western blot analyses}

Liver proteins were quantified by western blot analysis as follows using BioRad, (Hercules, CA) Criterion and
ChemiDoc systems following manufacturers' instructions. PGC1 $\alpha$ antibody was purchased from EMD Millipore, Billerica, MA, Cat\# ST1202. All other antibodies purchased from Santa Cruz Biotechnology, Santa Cruz, CA were as follows: FOXO1Ser256 Cat\# sc-101681; G6Pase- $\alpha$ Cat\# sc-27198; PEPCK Cat\# sc-32879; PPAR $\alpha$ Cat\# sc9000; SREBP-1 Cat\# sc-13551; mTORC Cat\# sc-8319; PPAR $\gamma$ Cat\# sc-7273; PGC1 $\beta$ Cat\# sc-67286, NFkB p65 Cat\# sc-8008; IKK $\alpha \beta$ Cat\# sc-7607; SOCS3 Cat\# sc-9023; JNK Cat\# sc-571; Actin Cat\# sc-47778. Criterion gradient tris-glycine precast gels, secondary antibodies, PVDF blotting membranes, molecular weight markers, and Enhanced Chemiluminescence (ECL) reagents were also purchased from BioRad. Samples from 8 SHR Vehicle, 8 SHR Bromocriptine treated rats, and 6 Wistar wild type controls were loaded onto the same 26 well Criterion gel along with the molecular weight markers; band intensity was compared only within the samples loaded onto the same gel. A housekeeping protein (actin) was concurrently quantified on all gels, and the test protein amount was normalized to actin in the Western blot analysis. Protein bands were quantified with BioRad ImageLab 4.1 software.

\section{Results}

Effect of SHR vs Wistar background and of Bromocriptine in SHR rats on Daily VMH Extracellular Monoamine Metabolite Profiles.

Figure 1A shows the 22 hour pattern of extracellular MHPG in the VMH of freely moving SHR rats treated with either bromocriptine or vehicle for 14 days compared to that of normotensive Wistar controls. A two-way ANOVA with repeated measures revealed a significant main effect of the bromocriptine treatment $\left(\mathrm{F}_{10}, 80=2.340, \mathrm{P}<0.05\right)$. SHR rats exhibited elevated VMH NE release relative to Wistar normal controls (66\% increase, $\mathrm{P}<0.0001)$. However, timed daily bromocriptine administration significantly reduced VMH MHPG of SHR rats compared with vehicle treated SHR rats $(65 \%, \mathrm{P}<0.0001)$.

Figure $1 \mathrm{~B}$ shows the 22 hour pattern of extracellular HVA in the VMH of freely moving SHR rats treated with either bromocriptine or vehicle for 14 days compared to that of normotensive Wistar controls. A two-way ANOVA with repeated measures revealed a significant strain treatment effect $\left(\mathrm{F}_{2}, 80=10.069, \mathrm{P}<0.005\right)$ and a significant interaction effect between treatment and time of day $\left(F_{20}, 80=1.99, \mathrm{P}<0.02\right)$. SHR rats had significantly lower extracellular VMH HVA content compared with normal Wistar rats $(29 \%, \mathrm{P}<0.001)$. However, extracellular VMH HVA content was not different between $\mathrm{BC}$ and vehicle treated SHR rats.

Figure $1 \mathrm{C}$ shows the 22 hour pattern of extracellular 5-HIAA in the VMH of freely living SHR rats treated with either bromocriptine or vehicle for 14 days compared to 


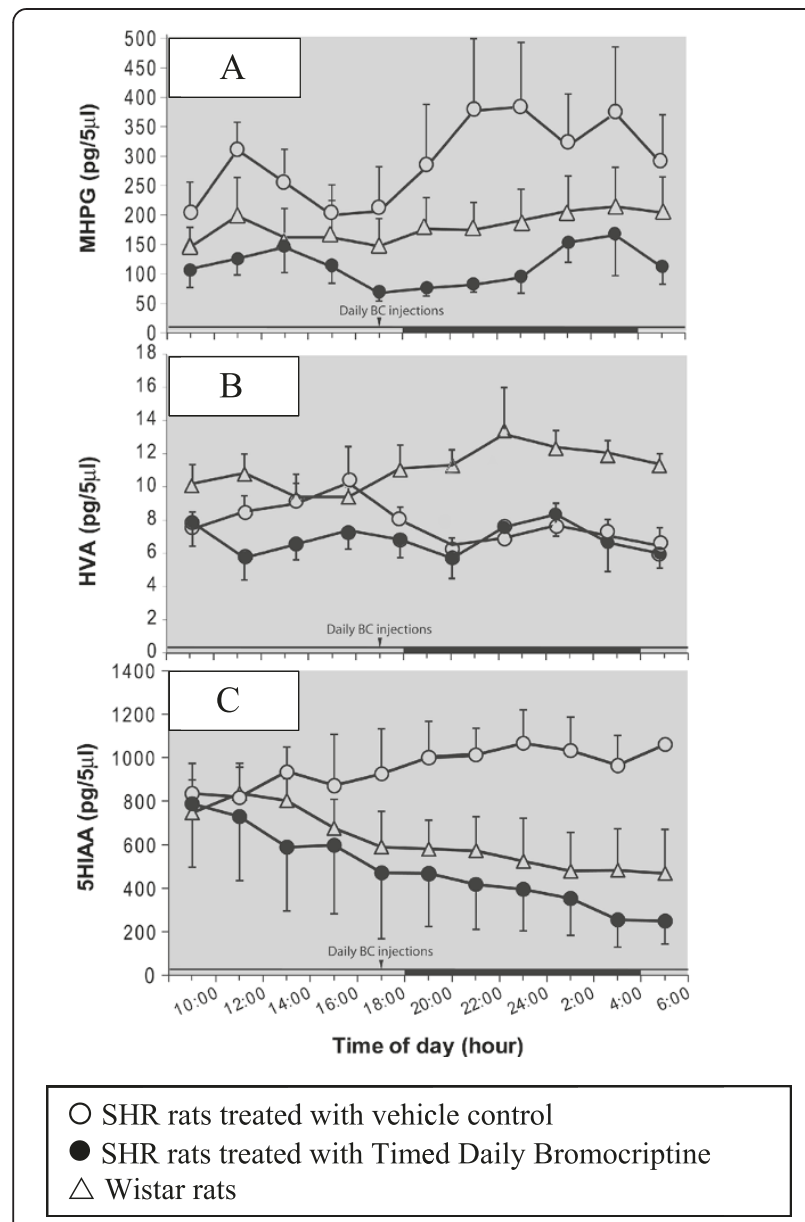

Figure 1 Effect of timed daily bromocriptine administration on ventromedial hypothalamic catecholamines. A. SHR rats exhibited elevated VMH NE release relative to Wistar normal controls $(P<0.0001)$. Timed daily bromocriptine administration significantly reduced VMH MHPG of SHR rats compared with vehicle treated SHR rats $(P<0.0001)$. B. SHR rats exhibited significantly lower extracellular VMH HVA content compared with normal Wistar rats $(p<0.001)$. C. SHR rats exhibited elevated VMH 5-HIAA release relative to Wistar normal controls $(P<0.0001)$. Timed daily bromocriptine administration significantly reduced VMH 5-HIAA of SHR rats compared with vehicle treated SHR rats $(P<0.0001)$ There was no significant difference in VMH 5-HIAA levels between SHR BC treated and Wistar rats.

that of Wistar control animals. There was a significant effect of the interaction between treatment and time of day $\left(\mathrm{F}_{20,80}=2.555, \mathrm{P}<0.002\right)$ by a two-way ANOVA with repeated measures. Post-hoc multiple-range test revealed a significant group difference on VMH 5-HIAA levels between SHR vehicle treated and BC treated (49\% reduction by $\mathrm{BC}$ treatment; $\mathrm{P}<0.0001)$ as well as between SHR and Wistar vehicle treated rats $(53 \%$ reduction in Wistars; $\mathrm{P}<0.0001)$. There was however, no significant difference on VMH 5-HIAA levels between SHR BC treated and Wistar rats.

\section{Effects of bromocriptine on metabolic and neuroendocrine factors potentiating metabolic syndrome}

Timed daily bromocriptine treatment for 14 days significantly reduced retroperitoneal fat pad weight of SHR rats by $42 \%(\mathrm{P}<0.0001)$, body weight and average daily food consumption slightly over the 14 day treatment period relative to vehicle treated controls (Figure 2). Such bromocriptine treatment also significantly reduced liver lipid content by $28 \%(\mathrm{P}=0.01)$. Bromocriptine treatment also reduced systolic blood pressure from $230 \pm$ $6 \mathrm{mmHg}$ to $188 \pm 6 \mathrm{mmHg}(\mathrm{P}=0.0003)$ and diastolic blood pressure from $185 \pm 11 \mathrm{mmHg}$ to $130 \pm 8 \mathrm{~mm}$ $\mathrm{Hg}(\mathrm{P}=0.001)$ towards the values observed in wild type Wistar rats (Figure 3).

Bromocriptine treatment reduced plasma glucose concentrations by $12 \%$ (from $112 \pm 3$ to $99 \pm 5 \mathrm{mg} / \mathrm{dl}$, $\mathrm{P}=0.03$ ), and plasma insulin by $55 \%$ from $6.9 \pm 1.0$ to $3.1 \pm 0.5 \mathrm{ng} / \mathrm{ml}(\mathrm{P}=0.007)$, resulting in a reduction in the homeostasis model assessment of insulin resistance (HOMA-IR) by $60 \%$ (from 47 to $18 \mu \mathrm{U} / \mathrm{ml} * \mathrm{mmol} / \mathrm{L}, \mathrm{P}=$ 0.004) relative to vehicle controls towards the values observed in wild type Wistar rats (Figure 4). Bromocriptine treatment produced significant reductions in plasma leptin by $62 \%$ (from $971 \pm 83$ to $374 \pm 41 \mathrm{pg} / \mathrm{ml}, \mathrm{P}<0.0001$ ), plasma norepinephrine by $41 \%$ (from $906 \pm 117$ to $538 \pm$ $69 \mathrm{pg} / \mathrm{ml}, \mathrm{P}<0.02$ ), and CRP by $15 \%$ (from $472 \pm 15$ to $402 \pm 29 \mathrm{mg} / \mathrm{l}, \mathrm{P}<0.05)$ levels, while it increased plasma adiponectin levels by $14 \%$ (from $10.4 \pm 0.5$ to $11.8 \pm$ $0.3 \mathrm{ng} / \mathrm{ml}, \mathrm{P}<0.03$ ) (Figure 5).

\section{Effect of bromocriptine on liver pro-inflammatory, gluconeogenic, fatty acid oxidative, and lipogenic proteins}

Bromocriptine treatment simultaneously reduced the levels of the liver inflammatory pathway activating transcription factor proteins NFKBp65, JNK, IKK $\alpha \beta$, and SOCS3 by $16 \%(\mathrm{P}=0.03), 22 \%(\mathrm{P}=0.003), 24 \%(\mathrm{P}=$ $0.004)$, and $38 \%(\mathrm{P}<0.0001)$, respectively relative to control values (Figure 6). Such bromocriptine treatment also reduced the levels of the hepatic gluconeogenic enzymes, PEPCK and G6Pase while increasing the levels of inactivated ser256 phosphorylated FOXO1 (thereby reducing the stimulatory effect of FOXO1 on gluconeogenesis), by $17 \% \quad(\mathrm{P}<0.04), 25 \% \quad(\mathrm{P}<0.01)$, $282 \%(\mathrm{P}=0.026)$, respectively (Figure 7$)$. Bromocriptine also reduced the hepatic levels of pro-FFA oxidative transcription factors, PGC1 $\alpha$, PPAR $\alpha$ and PPAR $\gamma$ by $26 \%(\mathrm{P}<0.01), 14 \%(\mathrm{P}<0.02)$, and $22 \%(\mathrm{P}=0.06)$, respectively (Figure 8 ). Bromocriptine also reduced the levels of liver triglyceride synthesis promoting proteins SREBP1, mTORC1, and PGC1 $\beta$ by $37 \%$, $(\mathrm{P}<0.001)$, $21 \%(P=0.001)$, and $23 \%(P=0.015)$, respectively, relative to SHR control (Figure 9). 

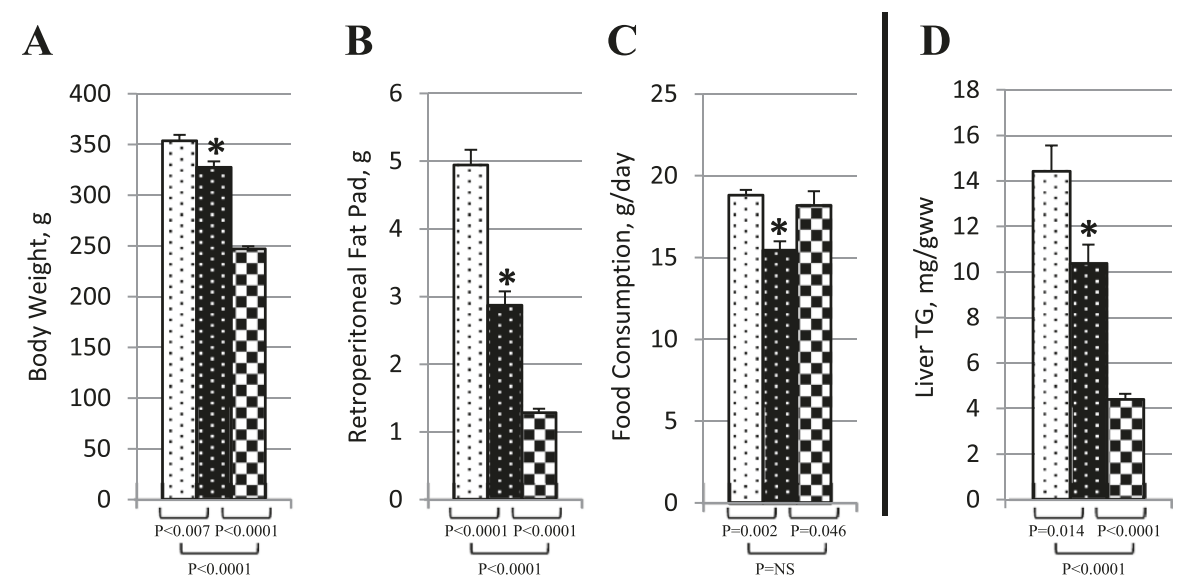

\begin{tabular}{|c|c|}
\hline \begin{tabular}{|l:}
$\vdots \vdots$ \\
\end{tabular} & SHR rats treated with vehicle control \\
\hline & SHR rats treated with \\
\hline & Timed Daily Bromocriptine \\
\hline$\theta$ & Wistar rats \\
\hline
\end{tabular}

Figure 2 Impact of timed daily bromocriptine or vehicle administration on body weight (Panel A), retroperitoneal fat pad (Panel B), food consumptions (Panel C) and liver triglycerides (Panel D). Values are means \pm SEM of 8 animals in each group. *Difference is statistically significant; P values are noted under each panel.

\section{Discussion}

This study is the first to demonstrate that dopamine agonist treatment ameliorates both major central and peripheral components of MS as evidenced by a simultaneous improvement in a range of neuroendocrine and metabolic pathologies including hypertension, obesity, hyperglycemia, hyperinsulinemia, insulin resistance, hyperleptinemia, increased liver lipid content, and hepatic pro-inflammatory protein pathway activation. Available evidence suggests that such wide spread influences on metabolism are largely via the hypothalamic/neuroendocrine axis $[1,2,10-12,14]$. Intracerebroventricular (icv) administration of bromocriptine to seasonal insulin resistant hamsters reduces body fat store levels, hyperinsulinemia, insulin resistance, and glucose intolerance. Information regarding the CNS targets for such icv dopamine agonist-induced improvements in seasonal insulin resistance indicates that modulation of monoamine activity at the hypothalamic VMH is at least one such CNS target $[11,12,14]$ among others (reviewed in [1]). Seasonal insulin resistance is associated with elevations in VMH NE and 5HT activities and importantly, infusion of exogenous NE and $5 \mathrm{HT}$ to the $\mathrm{VMH}$ of seasonal insulin sensitive animals to raise these monoamine levels to those observed in seasonal insulin resistant animals induces marked insulin resistance and beta cell dysfunction $[12,15]$ and this event has also been observed in nonseasonal animals as well [11]. Systemic bromocriptine treatment normalizes these VMH monoamine dysfunctions and insulin resistance in seasonal hamsters [14]. Also, preliminary data indicate that this influence of bromocriptine treatment to reduce insulin resistance can be largely attenuated by concurrent infusion of NE into the VMH (Cincotta, unpublished data). The present observations of a) increased VMH NE and 5HT activities in hypertensive, insulin resistant SHR versus normal Wistar rats and b) concurrent reductions in these VMH monoamine activities and amelioration of MS extend and corroborate these previous findings now in a non-seasonal, genetic model of MS and suggest that such hypothalamic aberrations may be a fundamental component of the neuroendocrine milieu supporting induction of MS. Several other animal models of insulin resistance including the ob/ob mouse, $\mathrm{db} / \mathrm{db}$ mouse, Zucker fatty rat, and offspring of malnourished or insulin treated pregnant rats all exhibit increased noradrenergic turnover within the VMH (reviewed in [1]).

Where and how bromocriptine is acting to produce these $\mathrm{VMH}$ corrections in monoamine activities is unknown, however sites involved may include at the $\mathrm{VMH}$ itself, as well as at the area of and surrounding the SCN $[3,4]$ the biological circadian pacemaker for the organism that communicates directly and indirectly (via the locus coeruleus and nucleus tractus solitarius) with the $\mathrm{VMH}$ and several other hypothalamic centers to regulate glucose tolerance [1]. Diminished dopaminergic activity at 


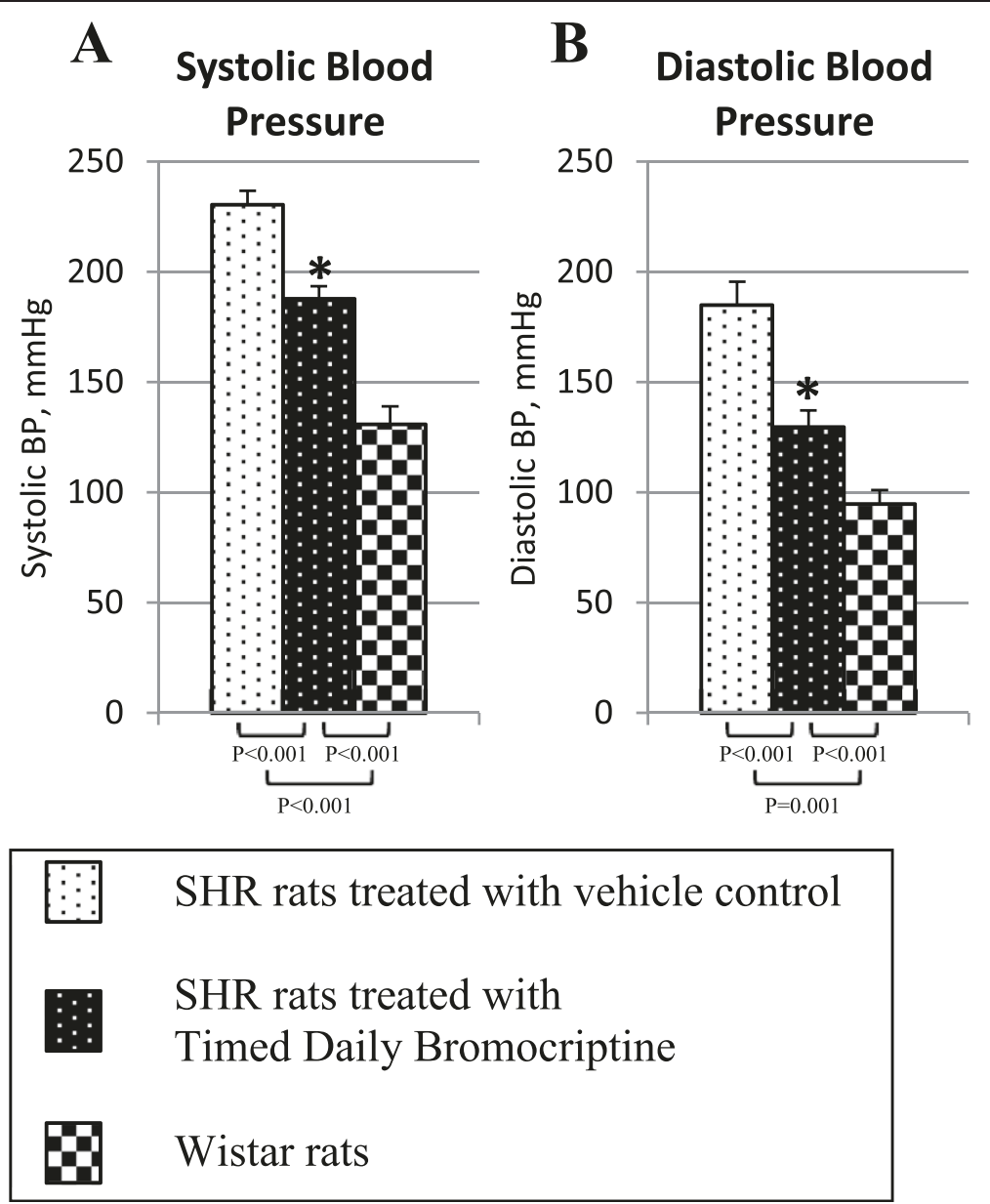

Figure 3 Impact of timed daily bromocriptine or vehicle administration on systolic (Panel A) and diastolic (Panel B) blood pressure. Values are means \pm SEM of 8 animals in each group. *Difference is statistically significant; $P$ values are noted under each panel.

the area of the SCN is characteristic of the seasonal insulin resistant state that is coupled with elevated VMH $\mathrm{NE}$ and 5HT activity levels [3] and neurotoxic lesion of dopaminergic neurons within this $\mathrm{SCN}$ area of insulin sensitive animals induces seasonal insulin resistance [4]. Interestingly, the SHR rat is well characterized as having reduced dopaminergic tone within the prefrontal cortex and ventrolateral stiatum $[16,17]$ and the current study now indicates that such is also the case within the VMH itself. We are currently investigating whether dopaminergic activities at the SCN are also reduced in these SHR rats as in seasonal insulin resistant states. We have observed such reduced dopaminergic activity at the SCN subsequent to high fat diet-induced insulin resistance [18].

Elevated VMH NE and 5HT activity produces a unique neuroendocrine profile characterized by increased plasma $\mathrm{NE}$, epinephrine, glucagon, insulin, free fatty acid (FFA), triglyceride, and leptin levels, increased sympathetic/ neuroendocrine drive for hepatic glucose output, adipose lipolysis, and vasoconstriction [11], as well as an increased insulin secretory response to glucose and hyperinsulinemia
$[11,15]$ that, as a composite, represents the hallmark of the MS. This neuroendocrine profile in turn is coupled to and/or potentiates insulin resistance, glucose intolerance, hyperlipidemia, obesity (reviewed in detail in [1] and hypertension [19]. Moreover, consistent with the observed normalization in elevated VMH NE and 5HT activities in this study, plasma levels of insulin, glucose, leptin, NE, and C-Reactive Protein were all reduced, and that of adiponectin was elevated following bromocriptine treatment in SHR rats. Furthermore, consistent as well with these neuroendocrine changes, HOMA-IR calculations indicate a marked improvement in insulin resistance following bromocriptine treatment. Additionally, plasma adiponectin levels are inversely correlated with and protect against both insulin resistance and fatty liver [20-22].

Likely due to decreased central (hypothalamic) dopaminergic tone as described above, SHR rats are hyperprolactinemic [23]. In turn, hyperprolactinemia has been demonstrated to potentiate fattening and insulin resistance in a variety of animal models and man (reviewed in [2]; [24-29]). In this regard it is critical to appreciate that 

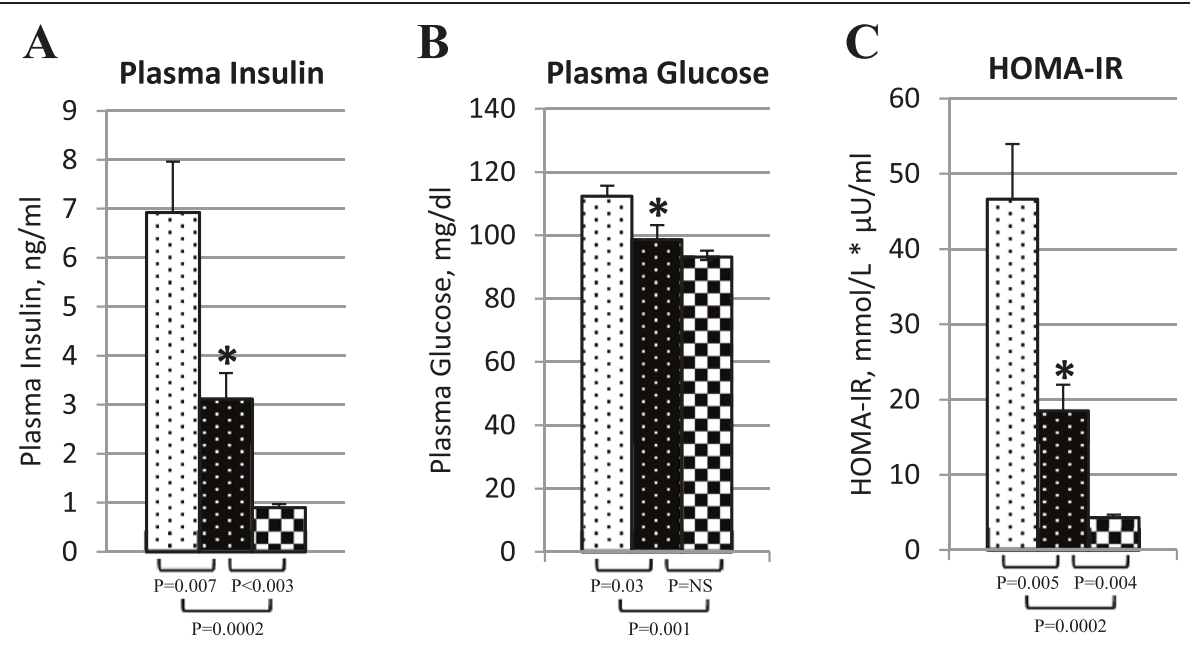

\begin{tabular}{|ll|}
\hline$::$ & SHR rats treated with vehicle control \\
$\vdots$ & $\begin{array}{l}\text { SHR rats treated with } \\
\text { Timed Daily Bromocriptine }\end{array}$ \\
日 & Wistar rats \\
\hline
\end{tabular}

Figure 4 Impact of timed daily bromocriptine or vehicle administration on plasma glucose (Panel A), plasma insulin (Panel B), and HOMA-IR index (Panel C). Values are means \pm SEM of 8 animals in each group. *Difference is statistically significant; P values are noted under each panel.
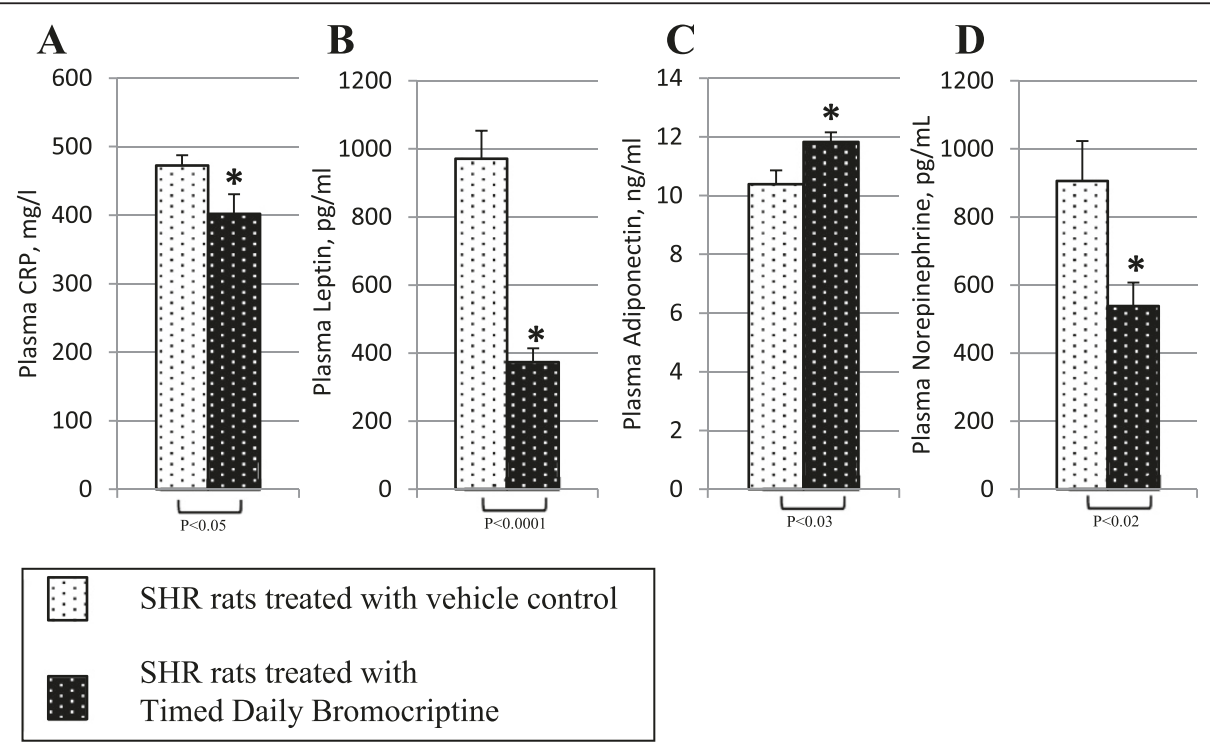

Figure 5 Impact of timed daily bromocriptine or vehicle administration on humoral modulators of metabolism and inflammation - plasma CRP (Panel A), plasma leptin (Panel B), plasma adiponectin (Panel C), and plasma norepinephrine (Panel D). Values are means \pm SEM of 8 animals in each group. *Difference is statistically significant; $P$ values are noted under each panel. 

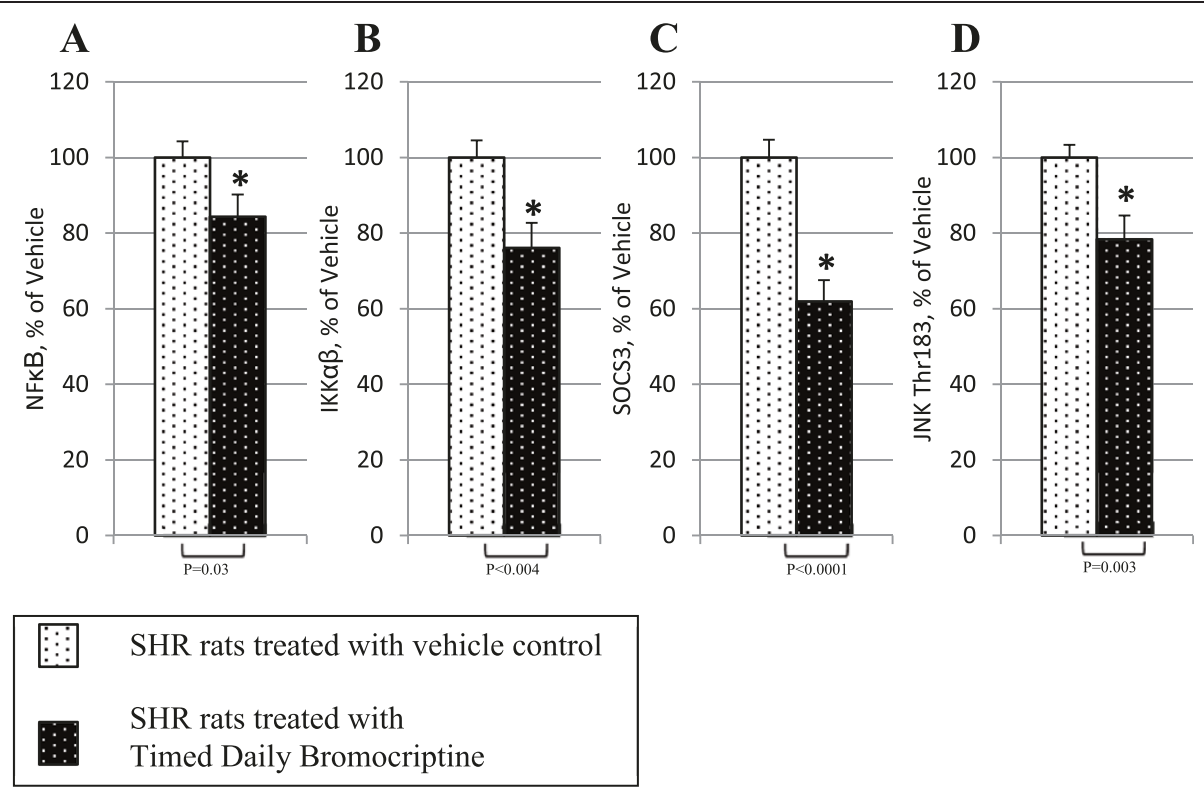

Figure 6 Impact of timed daily bromocriptine or vehicle administration on pro-inflammatory regulators - NFKBp65 (Panel A), IKKaß (Panel B), SOCS3 (Panel C), and JNK (Panel D). Proteins we quantified by Western blotting. Values are means \pm SEM of 8 animals in each group. *Difference is statistically significant; $P$ values are noted under each panel.

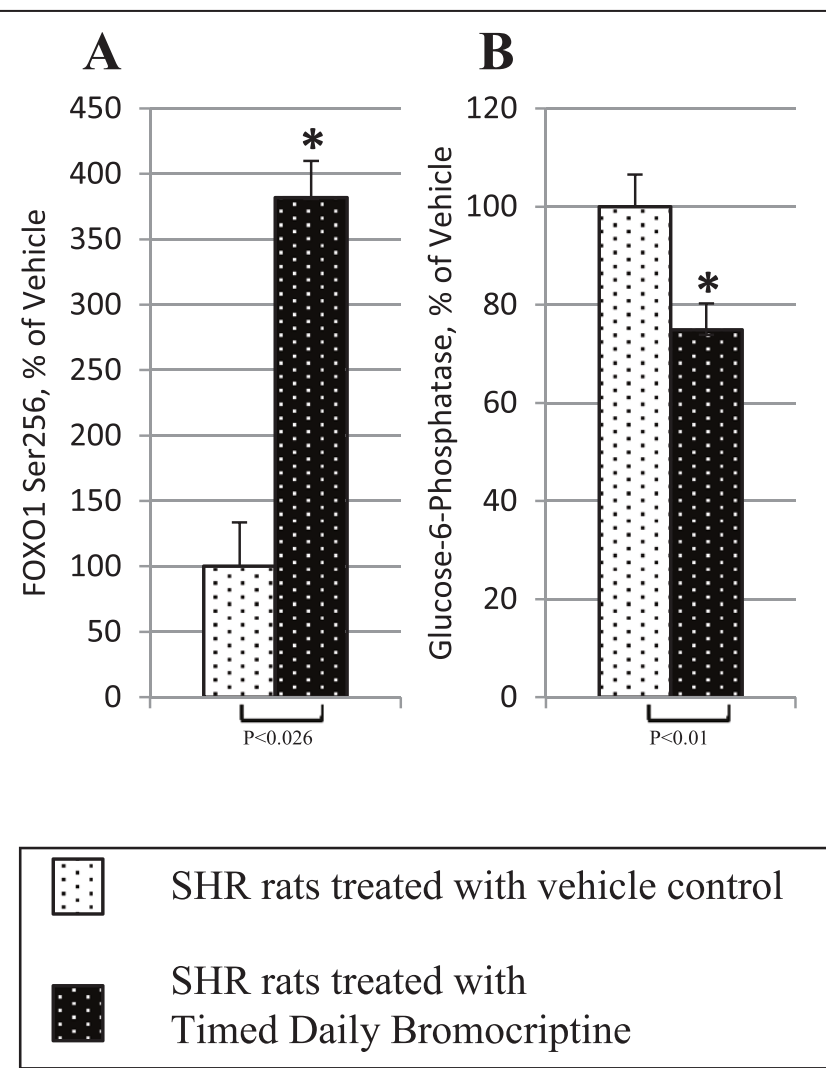

Figure 7 Impact of timed daily bromocriptine or vehicle administration on gluconeogenic pathway regulators - FOXO1 phosphorylated at Ser256 (Panel A), glucose-6-phosphatase (Panel B), and PEPCK (Panel C). Proteins we quantified by Western blotting. Values are means \pm SEM of 8 animals in each group. *Difference is statistically significant; $P$ values are noted under each panel. 

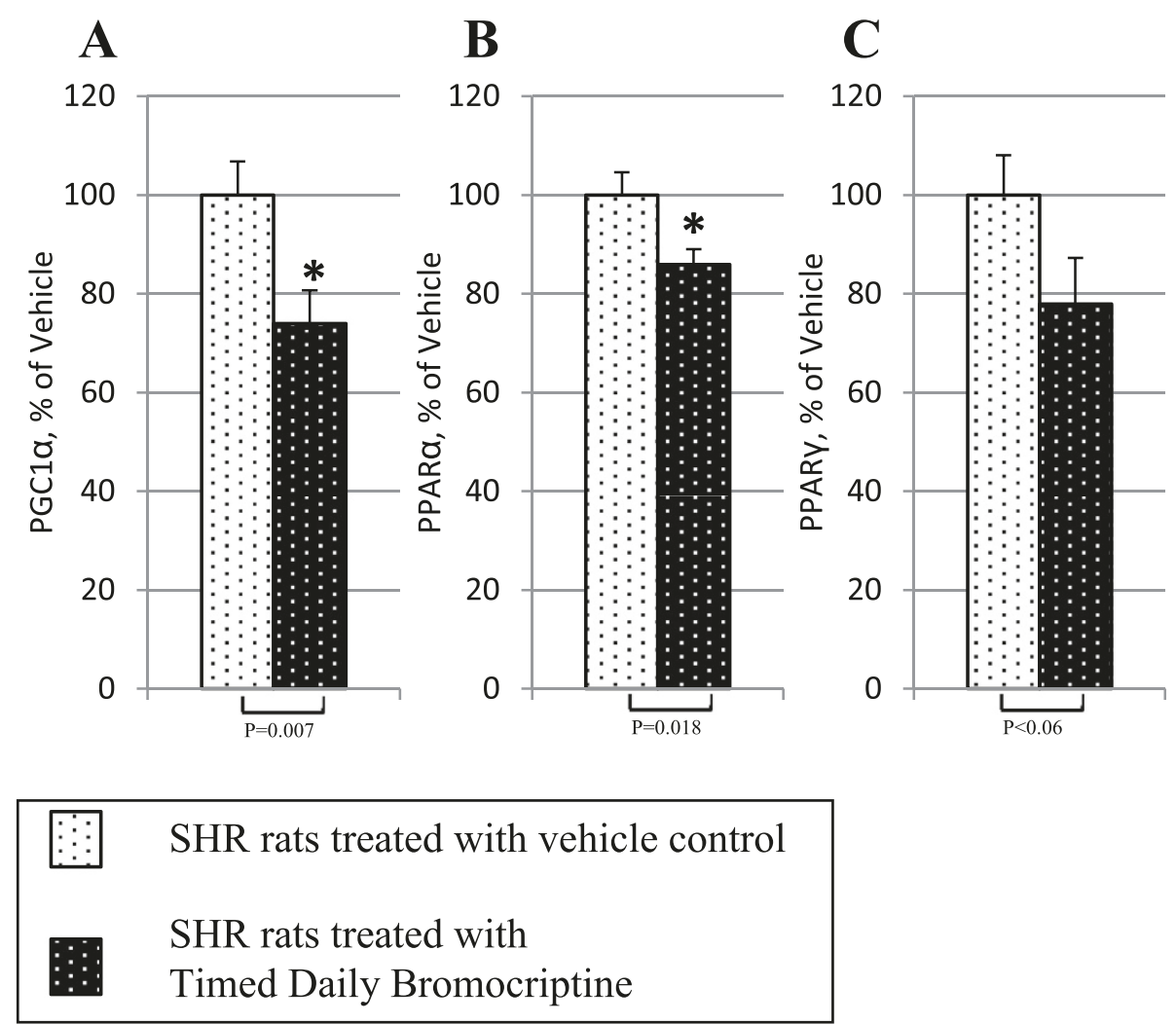

Figure 8 Impact of timed daily bromocriptine or vehicle administration on fatty acid oxidation activators - PGC1a (Panel A), PPARa (Panel B), and PPARY (Panel C). Proteins we quantified by Western blotting. Values are means \pm SEM of 8 animals in each group. *Difference is statistically significant; $P$ values are noted under each panel.

the circadian rhythm of plasma prolactin level differs in lean, insulin sensitive versus obese, insulin resistant animals [2]. More importantly, a marked circadian rhythm of metabolic responsiveness to prolactin exits in vertebrates such that injections of prolactin into lean, insulin sensitive animals at the time of day its level peaks in the blood of obese, insulin resistant animals induces the obese, insulin resistant state while injections of prolactin into obese, insulin resistant animals at the time of day its level peaks in the blood of lean, insulin sensitive animals produces a lean, insulin sensitive condition (reviewed in [2], [30,31]). Elevations of plasma prolactin levels can potentiate MS via decreasing hypothalamic dopamine release [32] thereby altering its signaling to the SCN to potentiate MS as described herein and elsewhere [1] that includes increasing lipogenic responsiveness to insulin in the periphery [33-35]. In the present study, bromocriptine, which is well known to effectively reduce hyperprolactinemia [36,37], was administered daily just after the time of day of the normal circadian peak in plasma prolactin levels in lean, insulin sensitive rats [31] prior to the end of the photoperiod to re-establish the normal dopaminergic circadian input activity to the SCN. Such timed administration would also likely function to re-establish a more normal daily plasma prolactin profile as observed in insulin sensitive rats [31], though such plasma prolactin levels were not measured in this study. Consequently, the metabolic effects of timed daily bromocriptine treatment observed in this study may in part derive from a reduction of plasma hyperprolactinemia and normalization of the daily rhythm of plasma prolactin level towards that of lean, insulin sensitive rats.

It should be noted that several studies have defined an inhibitory effect of acute direct/autocrine/paracrine dopamine on beta cell glucose stimulated insulin secretion (GSIS) in animals and man [38-41], with a potential role for gastrointestinal L-DOPA as an endogenous source for such physiological beta cell dopamine responses that may potentiate hyperglycemia [41]. Moreover, acute administration of bromocriptine itself has been shown to produce such an inhibitory effect on beta cell GSIS potentially via noradrenergic $\alpha 2$ receptors [42]. While such observations of acute direct dopamine activity to inhibit beta cell GSIS and thereby potentiate hyperglycemia may seem at odds with a multitude of observations indicating that circadian timed chronic dopamine agonist therapy improves glucose intolerance and hyperglycemia, a careful consideration of the available evidence suggests a different scenario. In 

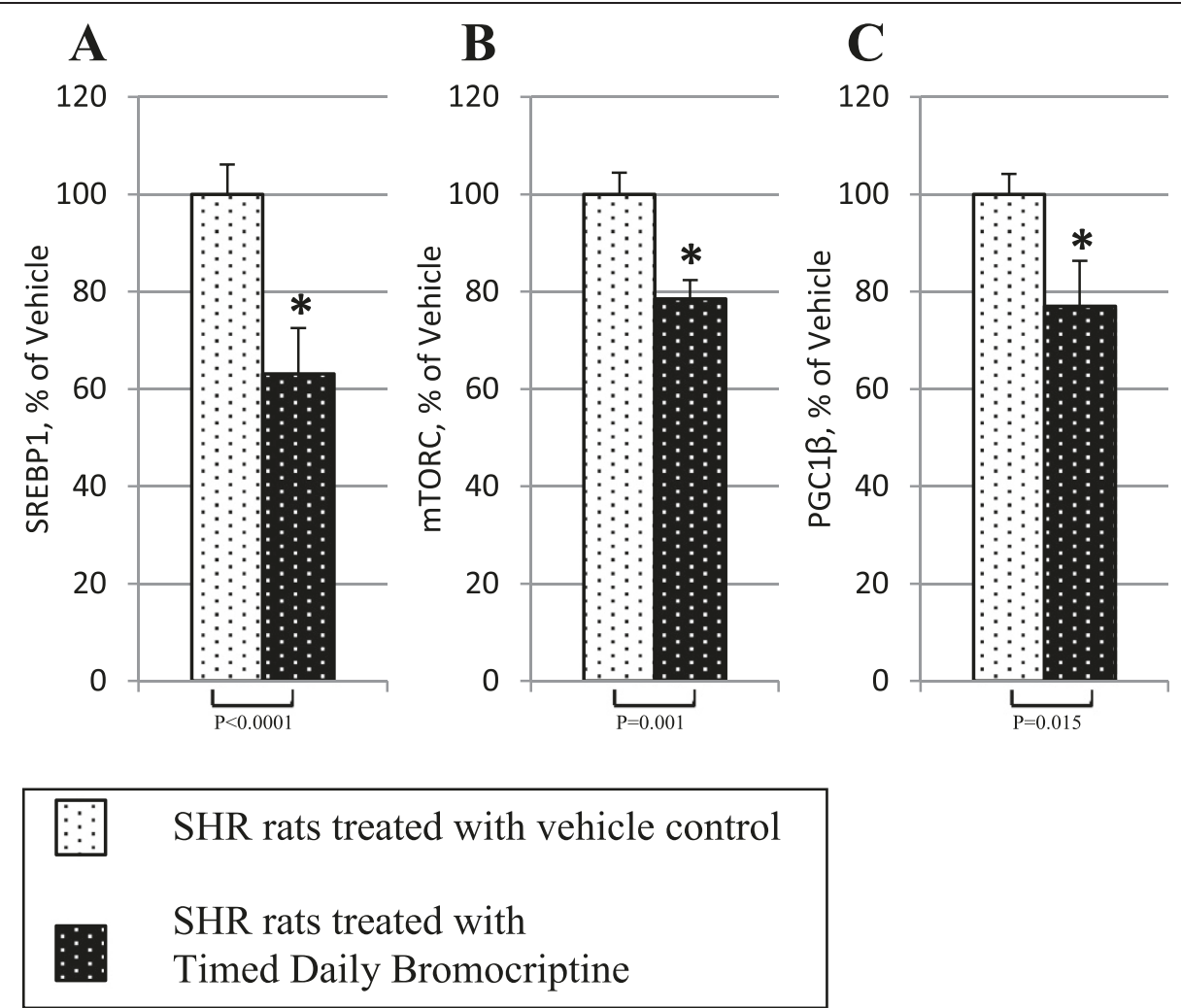

Figure 9 Impact of timed daily bromocriptine or vehicle administration on lipogenesis regulators - SREBP1 (Panel A), mTORC (Panel B), and PGC1 $\beta$ (Panel C). Proteins we quantified by Western blotting. Values are means \pm SEM of 8 animals in each group. *Difference is statistically significant; $P$ values are noted under each panel.

hyperinsulinemic glucose intolerant animals and man, chronic systemic timed bromocriptine treatment, that resets several hypothalamic circuits controlling metabolism $[3,4,10-12,14]$, reduces post glucose/meal challenge glucose area under curve (AUC) and insulin AUC simultaneously $[5,6,10,14,43,44]$. Importantly, this effect in such animals can be manifested with intracerebroventricular administration of bromocriptine at nearly one thousandth the effective systemic dose [10], and likely involves bromocriptine's effect to reduce elevated VMH NE and S activities and Paraventricular nucleus (PVN) Neuropeptide Y (NPY) and Corticotropin-releasing hormone (CRH) levels (present study, [11,12,14,45], that potentiate insulin resistance, direct hyperinsulinemia independent of insulin resistance, and increased beta cell GSIS concurrently $[1,11,12,15]$. However, in animals where glucose dysmetabolism progresses from impaired glucose tolerance to diabetes with beta cell dysfunction, such chronic dopamine agonist treatment reduces hyperglycemia while actually improving (increasing) GSIS, including the beta cell response to glucagon like peptide-1 $[46,47]$.

A plausible biological organization worth investigating that may unify these findings is the possibility that central (hypothalamic) circadian dopamine activities regulate beta cell function and insulin sensitivity in a coordinated fashion that would include regulation of paracrine dopamine activity at the beta cell. Under this postulate, in insulin resistant states, low hypothalamic dopamine activity allows for (potentiates) 1) an altered beta cell response to external (e.g., autonomic) stimuli that facilitates hyperinsulinemia and increased GSIS, as previous studies indicate [15], that may include low paracrine beta cell dopamine activity and 2) neuroendocrine mechanisms (as described in this study) facilitating insulin resistance to thereby establish a coordinated and controlled steady state hyperinsulinemic, insulin resistant condition (as observed in seasonal animals in the wild). Contrariwise, with appropriate circadian time increased hypothalamic dopaminergic activity, the hypothalamic metabolic control output coordinates an appropriate level of beta cell GSIS that may include increased (normal) paracrine dopamine activity and peripheral insulin sensitivity to maintain normal fasting and glucose tolerance glucose levels. Such a hypothalamic control system may contribute to the hyperbolic relationship of the "disposition index" that relates level of beta cell GSIS to insulin sensitivity [48] and we are currently investigating this possibility. 
Thus, these bromocriptine-induced changes in the hypothalamic-neuroendocrine axis as a composite may in part contribute to the observed bromocriptine-induced decrease in hypertension, liver fat content and insulin resistance in these SHR rats as described below.

To appreciate the impact of bromocriptine treatment on hepatic lipid and glucose metabolism observed in this study, one must first review the physiological relationship between these liver activities in normal and insulin resistant states. The physiological relationship between hepatic lipid and glucose metabolism differs markedly between insulin sensitive and insulin resistant states (reviewed in [49]). Under normal physiological conditions, circadian increases in hepatic lipogenesis are generally coupled to decreases in whole body and hepatic FFA oxidation and hepatic glucose output typically synchronized to the fed state or feeding phase of the day. Contrariwise, circadian decreases in lipogenesis are coupled to increased whole body and hepatic FFA oxidation and hepatic glucose output during the fasted state or circadian fasting phase of the day in rodents [2]. Such circadian organization of these metabolic activities synchronizes the animal with its daily cyclic environment of food availability and internal locomotor activity rhythm (food seeking/gathering, feeding/lipogenesis synchronized temporally as are sleeping/fasting/FFA oxidation), thereby enhancing survival potential [2]. By comparison, in insulin resistant states, hepatic lipogenesis, FFA oxidation, and hepatic glucose output are all simultaneously increased at their respective circadian peak activity times (reviewed in [1]). In studies of humans as well, hepatic insulin resistance respecting control of glucose production associates most often with increased, not decreased, hepatic lipid synthesis/content and FFA oxidation [50-57]. Although a variety of genetic manipulations that result in increased hepatic FFA oxidation have been demonstrated to improve hepatic insulin resistance, primarily by decreasing hepatic lipid content (e.g., triacylglycerol, diacylglycerol, acyl-CoA, lysophosphatidic acid, and/or phosphatidic acid) [58-64], hepatic FFA oxidation is a potent stimulus for gluconeogenesis, reactive oxygen species generation (ROS), inflammatory cytokine production and insulin resistance $[17,19-22,49-55,57,65,66]$. Moreover, reduction of hepatic FFA oxidation by genetic manipulations that actually enhance fatty liver is still coupled to improved insulin sensitivity or glucose tolerance [67-73], reviewed in [49]. In the SHR rat model investigated herein, as in human insulin resistant states such as obesity and fatty liver [50-55,57], insulin resistance is coupled to increased hepatic lipid content, FFA oxidative activity/capacity, and gluconeogenic activity/capacity.

In obese, hyperinsulinemic, insulin resistant states such as the aged SHR rat, increased hepatic fatty acid level resulting from increased adipose lipolysis and subsequent plasma FFA uptake, dietary fat intake and/or de novo lipogenesis can potentiate increased inappropriate hepatic fat accumulation (e.g., steatosis) and fatty acid oxidation with ensuing cellular pathological consequences, termed lipotoxicity $[49,56,65,74-77]$, reviewed in $[78,79]$. Lipotoxicity manifested as excess production of triacylglycerol intermediates (e.g., diacylglycerol, acyl-CoA, lysophosphatidic acid, phosphatidic acid) at specific and as yet poorly understood intracellular sites and/or overload in substrate driven fatty acid oxidation that ultimately results in incomplete fatty acid oxidation with the generation of oxidation intermediates (acid soluble intermediates) can facilitate reactive oxygen species (ROS) production and subsequent pro-inflammatory protein synthesis such as NFKB, JNK, and SOCS3 $[65,77,80-82]$. Such increased fatty acid oxidation also induces an increase in mitochondrial tricarboxylic acid cycle activity (though inadequate for the supply of fatty acids), increased gluconeogenic precursor generation, and subsequent respiratory dysfunction leading to increased generation of ROS $[4,8-10,50-55,57]$ that also stimulate such pro-inflammatory protein synthesis [55-57,83-86] and stimulate PGC1 and FOXO1 synthesis [87], transcription factors that potentiate a further increased drive for FFA oxidation and gluconeogenesis [70,74,87-97]. Increases in hepatocellular levels of ROS and these pro-inflammatory proteins can also potentiate insulin resistance respecting insulin inhibition of gluconeogenesis and can simultaneously facilitate hepatic lipogenesis as more fully discussed below.

Regarding the influence of hepatic NFKB, JNK, and SOCS3 on gluconeogenesis, increased activity of any of these proteins can induce increased gluconeogenesis by inhibiting hepatic insulin signaling [53,80,81,84,98-101] and either concurrently or independently potentiating activation of FOXO1 $\alpha[77,84]$, a key transcription factor for the induction of the gluconeogenic enzymes, G6Pase and PEPCK $[93,102]$ (and for the induction of enzymes that damage respiratory complexes leading to increased ROS production and subsequent insulin resistance) [103]. Increases in JNK transcription can be induced by incomplete FFA oxidation and ROS production, as described above, as well as by local or circulating cytokines $[53,99]$ and JNK is a strong stimulus for activation of FOXO1 $\alpha$ [84]. Liver FOXO1 $\alpha$ activation has been coupled to the insulin resistant diabetic phenotype $[58-64,87,104]$. Moreover, hepatic PGC1 $\alpha$, a transcription factor that associates with FOXO1 $\alpha$ to induce transcription of gluconeogenic enzymes, induces hepatic insulin resistance and is itself elevated in diabetes [89-91,93-96,105]. Increased PGC1 $\alpha$ level is also a strong activator of fatty acid oxidation in liver and this increased activity can function to maintain the proinflammatory/gluconeogenic state by providing for excess fat oxidation as described above. Increases in hepatic SOCS3, by JNK or other cytokine/ 
oxidative stress factors, contribute to increased hepatic glucose output by inducing insulin resistance (by inactivating IRS1/2 and/or inducing PGC1 $\alpha$ and FOXO1) [106]. Low-level activation of NFKB stimulates the production of IL-1 $\beta$, IL- 6 , and TNF $\alpha$ that can in turn a) stimulate the activation and/or synthesis of NFKB, JNK, and SOCS3 and b) additionally directly inhibit the insulin signaling pathway $[53,80,99,101]$. Therefore, simultaneous increases in NFKB, JNK, and SOCS3 can contribute to a strong and potentially self-sustaining pro-gluconeogenic/pro FFA oxidative environment.

Activation of NFKB, JNK, and SOCS3 also stimulates hepatic lipid production. Increases in hepatic JNK (via IL-6, TNF $\alpha$, FFA, or oxidative stress) or NFKB can induce SOCS3 transcription that in turn can induce SREBP1, a potent transcription factor for several lipogenic enzymes within the liver [57]. Furthermore, this activity may be enhanced by PGC1 $\beta$, a strong coactivator of SREBP1 to stimulate lipogenic gene expression [89-91,93-96,107]. Hepatic reduction of JNK or NFkB [108-110] or suppression of SOCS3 [101] reduces fatty liver. Additionally, other studies have shown that increases in hepatic ROS level are also a stimulus for SREBP1 synthesis without effect on insulin signaling through IRS-1 or AKT [111-114]. Hepatic insulin resistance is also coupled to enhanced liver PPAR $\gamma$ levels that function to increase lipid synthesis [115-117]. It should be appreciated that hepatic gene knock-out studies, as opposed to suppression studies, for any one of these three proteins may yield results indicating exacerbation instead of reduction of the hepatic gluconeogenic/lipogenic phenotype due to overcompensation of redundant proinflammatory pathways [118], however the overwhelming composite of available evidence indicates that moderate reductions of elevated levels of these proteins towards the normal range is coupled to a reduction of the gluconeogenic/lipogenic liver phenotype as outlined above. Finally, another master regulator of hepatic lipogenesis, mTORC1, not only induces lipogenic activity but can potentiate insulin resistance via stimulation of SOCS3 expression [119], which can also stimulate lipogenesis via SREBP1 as described above. Therefore, moderate and simultaneous increases in hepatic ROS [111-114] and/or NFKB, JNK, and SOCS3 can interact to facilitate the induction and maintenance of a more gluconeogenic/FFA oxidative and lipogenic liver via simultaneous induction of the master activators of lipogenesis (PGC1 $\beta$, SREBP1, and mTORC) and gluconeogenesis (FOXO1, PGC1 $\alpha$ ), concurrently with induction of FFA-oxidative activity (PGC1 $\alpha$, PPAR $\alpha$ ), activity of which in turn sustains the increase in ROS and pro-inflammatory protein environment and a vicious cycle is born. These ROS and proinflammatory proteins may be induced by a high fat diet (with consequent over-supply of FFAs to liver) $[50-55,57]$ or by an altered neuroendocrine organization (e.g., low SCN dopamine and high VMH NE and 5HT activities) independent of a high fat diet that re-programs metabolism favoring a liver biochemistry inducing their production as in the SHR rats held on a regular (low-fat) diet in this study [1]. This neuroendocrine driven hepatic pro-inflammatory state may occur with even moderately increased antecedent incomplete FFA oxidation, mitochondrial dysfunction, ER stress and ROS over-generation.

Although typically viewed as pathology, such an endogenous programmed mechanism for increased hepatic lipid and glucose production can have substantive survival benefits for animals in the wild during seasons of low food availability. During long seasons of low food (and glucose) supply, a programmed induction of increased hepatic lipogenesis and secretion, coincident with increased hepatic glucose output, under the setting of insulin resistance would allow for increased peripheral utilization of mobilized fat and CNS utilization of (hepatic) glucose (that has a predominant requirement for glucose as a fuel source) and such alterations in metabolism would increase odds of organismal survival under this environmental stress. Our previous work indicates that the seasonal obese, insulin resistant state, characterized by increased hepatic lipogenesis and glucose output, can be manifested by alterations in hypothalamic activities characterized by low dopaminergic tone at the area of the SCN and increased noradrenergic and serotonergic tone at the VMH without any alteration in diet $[3,4,11,12,14,15]$ and timed bromocriptine treatment reverses both this hypothalamic activity and the heightened hepatic lipogenic/ gluconeogenic metabolic state $[5,6,8-10,14]$.

In the present study, bromocriptine decreased abnormally elevated VMH NE and serotonin levels that are known not only to be associated with insulin resistance but actually to induce hyperinsulinemia, insulin resistance, glucose intolerance and fatty liver, increased noradrenergic drive to adipose leading to increased lipolysis (and FFA flux to liver), and increased plasma norepinephrine level potentiating increased gluconeogenesis $[11,12,14,15,120]$. Bromocriptine-induced decrease in liver lipid content resulting from decreased plasma insulin levels $[5,6,10]$ and present study, decreased hepatic lipogenesis $[6,9]$ and/or decreased plasma FFA availability [5] may reduce over-stimulated fatty acid oxidation and subsequent incomplete fatty acid oxidation metabolites (acid soluble metabolites) and by-products (such as ceramides, acylCoAs, diacylglycerol, and lipid peroxides) [50-55,57,78,79] and subsequent mitochondrial derived ROS [78,79] collectively thereby simultaneously reducing $\mathrm{NFKB}$, JNK, and SOCS3 levels as observed in this study. Under conditions of insulin resistance, ablation or elimination of any one of these 3 pro-inflammatory protein pathways can be compensated for by up-regulation of the others with 
maintenance of insulin resistance [98,101]. However this does not appear to be the case with bromocriptine treatment in this study. Bromocriptine reduced all three proinflammatory protein levels concurrently that resultantly can act to contribute to the observed bromocriptineinduced simultaneous reductions in the master activators of lipogenesis and gluconeogenesis as described above. The coupled effects of bromocriptine to concomitantly reduce liver activated FOXO1 (induced increase in FOXO1ser256), G6Pase, and PEPCK levels on the one hand and SREBP1, mTORC, PPAR $\gamma$, and PGC1 $\beta$ levels on the other offer mechanisms by which bromocriptine treatment reduced both plasma glucose level and hepatic fat content, respectively. The effect of bromocriptine to reduce hepatic gluconeogenic capacity itself may derive in part from its induced reduction of hepatic FFA oxidative capacity as assessed by the reduced levels of hepatic PGC1 $\alpha$ and PPAR $\alpha$ in bromocriptine-treated animals, levels of which are elevated in insulin resistant states [50-55,57,89-91,93-96]. In addition to its effects to reduce hepatic PGC1 $\alpha$ and PPAR $\alpha$, bromocriptine-induced decreases in plasma FFA and liver lipid synthesis may function to reduce liver FFA oxidative capacity and subsequently to reduce ROS production and inflammatory protein(s) synthesis in turn reducing insulin resistance and gluconeogenesis while also breaking the vicious positive feedback cycle on this pathway induced by the ROS.

Since bromocriptine can reverse insulin resistance, glucose intolerance and fattening by its i.c.v. injection, the present observed effects on hepatic glucose and lipid metabolism may be the indirect result of its treatment effects on the entire neuroendocrine axis, not only by influencing the VMH and SCN as described above and reducing neuropeptide $\mathrm{Y}$ and corticotropin levels in the paraventricular hypothalamus as previously described [45], and such is the topic of our ongoing investigation. Such centrally elicited effects of bromocriptine do not preclude any additional direct peripheral effects of the therapy to produce the results described herein and such considerations are the focus of our ongoing investigation. The bromocriptine effect on liver insulin signaling pathway proteins and redox status as it relates to its impact on lipogenesis and gluconeogenesis remain as yet undetermined and the results of this study suggest that such investigations are warranted. It should be appreciated that while the small reduction in food consumption with bromocriptine treatment observed in this study may contribute to its overall effects on metabolic status, such small reductions (in low fat content food) are not large enough to explain the large reductions in body fat, liver fat, insulin resistance, or hypertension, and indeed previous studies have demonstrated improvements in insulin resistance and body fat of bromocriptine treated animals without any change in feeding $[5,6,10]$.
Respecting neuroendocrine impact on blood pressure in MS, reductions in hyperleptinemia and elevated plasma NE can interact to reduce vasoconstriction and hypertension (reviewed in [1]) and marked improvements in these plasma parameters and of hypertension were observed following bromocriptine treatment of SHR rats. Moreover, we have observed a strong hypertensive effect of $\mathrm{VMH}$ NE plus 5HT infusion into the VMH of normal rats [10] and in the present study bromocriptine treatment reduced elevated VMH NE and 5HT activities in these SHR rats to normal levels. Previous studies have likewise documented an anti-hypertensive effect of bromocriptine in SHR rats and investigations into mechanisms of this bromocriptineinduced effect suggest both complex central and peripheral actions of the agent to reduce sympathetic tone, plasma NE level, and vasoconstriction [106,121-127].

In summary, timed bromocriptine treatment reduces overactive noradrenergic and serotonergic activities at the VMH of hypertensive, obese, insulin resistant SHR rats, activities of which have previously been demonstrated to predispose to insulin resistance, hypertension, and fattening ([7], reviewed in [1]). This bromocriptine treatment also reduces hypertension and neuroendocrine stimuli for hepatic insulin resistance and lipid accumulation, particularly increased sympathetic drive, hyperinsulinemia, hyperleptinemia, and reduced plasma adiponectin. Its effects to reduce liver lipid content and gluconeogenic capacity at the level of the liver are coupled to a reduction of multiple activated pro-inflammatory protein pathways that concurrently induce transcriptional master activators of lipogenesis and gluconeogenesis. Simultaneously, such bromocriptine treatment also reduces major transcription factors that increase FFA oxidative capacity of the liver, which in and of itself may contribute to the drug-induced reduction in gluconeogenic enzyme levels. Available evidence suggests that these peripheral effects of bromocriptine are likely functionally linked to its impact on hypothalamic, particularly SCN and VMH activities.

\section{Abbreviations \\ 5HIAA: 5-hydroxy-indoleacetic acid; 5HT: 5-hydroxytryptamine; ANOVA: Analysis of variance; AUC: Area under curve; CNS: Central nervous system; $\mathrm{CRH}$ : Corticotropin-releasing hormone; ECL: Enhanced chemiluminescence; ER: Endoplasmic reticulum; FFA: Free fatty acids; GSIS: Glucose stimulated insulin secretion; HALO: Hours after light onset; HOMA-IR: Homeostatic model assessment - insulin resistance; HVA: Homovanillic acid; Icv: Intracerebroventricular; i.p.: Intraperitoneal; MS: Metabolic syndrome; MHPG: 3-methoxy-4-hydroxy-phenylglycol; NE: Norepinephrine; NPY: Neuropeptide Y; PVDF: Polyvinylidene difluoride; PVN: Paraventricular nucleus; ROS: Reactive oxygen species; S: Serotonin; SEM: Standard error of the mean; SCN: Suprachiasmatic nuclei; \\ SHR: Spontaneously hypertensive rat; VMH: Ventromedial hypothalamus.}

\section{Competing interests}

Michael Ezrokhi, Shuqin Luo, Yelena Trubitsyna, and Anthony H. Cincotta are all employees of VeroScience, a company that developed and via partnership markets Cycloset, the active agent of which is bromocriptine, for the treatment of type 2 diabetes in the U.S. Anthony H. Cincotta serves as the President and 
Chief Scientific Officer and is a shareholder of Veroscience. VeroScience holds patents relating to the metabolic effects of bromocriptine.

\section{Authors' contributions}

ME made substantial contributions to 1) conception and design, acquisition of data, analysis and interpretation of data; 2) was involved in drafting the manuscript and revising it critically for important intellectual content; 3) gave final approval of the version to be published; and 4) agrees to be accountable for all aspects of the work. SL made substantial contributions to 1) conception and design, acquisition of data, analysis and interpretation of data; 2) was involved in drafting the manuscript and revising it critically for important intellectual content; 3) gave final approval of the version to be published; and 4) agrees to be accountable for all aspects of the work. YT made substantial contributions to 1) acquisition of data, analysis of data; 2) was involved in drafting the manuscript and revising it critically for important intellectual content; 3) gave final approval of the version to be published; and 4) agrees to be accountable for all aspects of the work. AHC made substantial contributions to 1) conception and design, acquisition of data, analysis and interpretation of data; 2) was involved in drafting the manuscript and revising it critically for important intellectual content; 3) gave final approval of the version to be published; and 4) agrees to be accountable for all aspects of the work. All authors read and approved the final manuscript.

Received: 28 May 2014 Accepted: 16 September 2014

Published: 25 September 2014

\section{References}

1. Cincotta AH: Hypothalamic role in the insulin resistance syndrome. In Insulin Resistance and Insulin Resistance Syndrome, Frontiers in Animal Diabetes Research Series. Edited by Hansen B, Shafrir E. London: Taylor and Francis; 2002:271-312.

2. Meier $\mathrm{AH}$, Cincotta $\mathrm{AH}$ : Circadian rhythms regulate the expression of the thrifty genotype/phenotype. Diabetes Rev 1996, 4:464-487. http://www. scopus.com/scopus/inward/record.url?eid=2-s2.0-0030445765\&partnerlD= K84CVKBR\&rel=3.0.0\&md5=6330c11e945d55379158dd0e8f9f1438.

3. Luo S, Luo J, Cincotta AH: Suprachiasmatic nuclei monoamine metabolism of glucose tolerance versus intolerant hamsters. Neuroreport 1999, 10:2073-2077.

4. Luo S, Luo J, Meier AH, Cincotta AH: Dopaminergic neurotoxin administration to the area of the suprachiasmatic nuclei induces insulin resistance. Neuroreport 1997, 8:3495-3499.

5. Cincotta $\mathrm{AH}, \mathrm{Mac}$ Eachern TA, Meier AH: Bromocriptine redirects metabolism and prevents seasonal onset of the obese hyperinsulinemic state in Syrian hamsters. Am J Physiol 1993, 264:E285-E293.

6. Cincotta AH, Schiller BC, Meier AH: Bromocriptine inhibits the seasonally occurring obesity, hyperinsulinemia, insulin resistance and impaired glucose tolerance in the Syrian hamster, Mesocricetus auratus. Metabolism 1991, 40:639-644

7. Luo S, Ezrokhi M, Trubitsyna Y, Cincotta AH: High Fat Feeding Initiates Insulin Resistance Syndrome Inducing Neuronal Pathways in the Ventromedial Hypothalamus (VMH) [abstract]. Diabetes 2012, 61(Suppl 1):1912P.

8. Cincotta $\mathrm{AH}$, Meier $\mathrm{AH}$ : Bromocriptine inhibits in vivo free fatty acid oxidation and hepatic glucose output in seasonally obese hamsters (Mesocricetus auratus). Metabolism 1995, 44:1349-1355.

9. Cincotta $\mathrm{AH}, \mathrm{Meier} \mathrm{AH}$ : Prolactin permits the expression of a circadian variation in lipogenic responsiveness to insulin in hepatocytes of the golden hamster (Mesocricetus auratus). J. Endocr 1985, 106:173-176.

10. Luo S, Liang Y, Cincotta AH: Intracerebroventricular administration of bromocriptine ameliorates the insulin-resistant/glucose intolerant state in hamsters. Neuroendocrinology 1999, 69:160-166

11. Cincotta AH, Luo S, Zhang Y, Bina G, Jetton TL, Scislowski PWD: Chronic infusion of norepinephrine into the $\mathrm{VMH}$ of normal rats induces the obese-glucose intolerant state. Am J Physiol 2000, 278:R435-R444.

12. Luo S, Luo J, Cincotta AH: Chronic ventromedial hypothalamic infusion of norepinephrine and serotonin promotes insulin resistance and glucose intolerance. Neuroendocrinology 1999, 70:460-465.

13. Aleixandre De Artiñano A, Miguel Castro M: Experimental rat models to study the metabolic syndrome. Br J Nutr 2009, 102:1246-1253.
14. Luo S, Meier AH, Cincotta AH: Bromocriptine reduces obesity, glucose intolerance, and extracellular monoamine metabolite levels in the ventromedial hypothalamus of Syrian hamsters. Neuroendocrinology 1998, 68:1-10.

15. Liang $Y$, Luo $S$, Cincotta AH: Long-term infusion of norepinephrine plus serotonin into the ventromedial hypothalamus impairs pancreatic islet function. Metabolism 1999, 48:1287-1289.

16. Fujita S, Kazunori A, Lee J, Uchida T, Koshikawa N, Cools AR: Decreased postsynaptic dopaminergic and cholinergic functions in the ventrolateral striatum of spontaneously hypertensive rat. Eur J Pharmacol 2004, 484:75-82.

17. Linthorst ACE, Van Don Busse M, De Jong W, Versteeg DHG: Electricallystimulated $[3 \mathrm{H}]$ dopamine and $[14 \mathrm{C}]$ acetylcholine release from nucleus accumbens slices: difference between spontaneously hypertensive rats and Wistar-Kyoto rats. Brain Res 1990, 509:266-272.

18. Luo S, Zhang Y, Ezrokhi M, Trubitsyna Y, Cincotta AH: High fat feeding abolishes the insulin-sensitizing peak in circadian dopamine activity at the biological clock [abstract]. Diabetes 2014, 63(Suppl 1):1824P

19. Luo S, Ezrokhi M, Trubitsyna Y, Cincotta AH: Elevation of serotonin activity within the ventromedial hypothalamus $(\mathrm{VMH})$ induces the hypertensive insulin resistant state in rats [abstract]. Diabetes 2011, 60(Suppl 1):A128.

20. Asano T, Watanabe K, Kubota N, Gunji T, Omata M, Kadowaki T, Ohnishi S: Adiponectin knockout mice on high fat diet develop fibrosing steatohepatitis. J Gastroenterol Hepatol 2009, 24:1669-1676.

21. Asterholm IW, Scherer PE: Enhanced metabolic flexibility associated with elevated adiponectin levels. Am J Pathol 2010, 176:1364-1376.

22. Peng Y, Rideout D, Rakita S, Sajan M, Farese R, You M, Murr MM: Downregulation of adiponectin/AdipoR2 is associated with steatohepatitis in obese mice. J Gastrointest Surg 2009, 3:2043-2049.

23. Sowers JR, Resch G, Tempel G, Herzog J, Colantino M: Hyperprolactinaemia in the spontaneously hypertensive rat. Acta Endocrinol (Copenh) 1979, 90:1-7.

24. Berinder K, Nyström T, Höybye C, Hall K, Hulting AL: Insulin sensitivity and lipid profile in prolactinoma patients before and after normalization of prolactin by dopamine agonist therapy. Pituitary 2011, 14:199-207.

25. Tuzcu A, Yalaki S, Arikan S, Gokalp D, Bahcec M, Tuzcu S: Evaluation of insulin sensitivity in hyperprolactinemic subjects by euglycemic hyperinsulinemic clamp technique. Pituitary 2009, 12:330-334.

26. Tuzcu A, Bahceci M, Dursun M, Turgut C, Bahceci S: Insulin sensitivity and hyperprolactinemia. J Endocrinol Invest 2003, 26:341-346.

27. Foss MC, Paula FJ, Paccola GM, Piccinato CE: Peripheral glucose metabolism in human hyperprolactinaemia. Clin Endocrinol (Oxf) 1995, 43:721-726.

28. Serri $O$, Beauregard H, Rasio E, Hardy J: Decreased sensitivity to insulin in women with microprolactinomas. Fertil Steril 1986, 45:572-574.

29. Dos Santos Silva CM, Barbosa FR, Lima GA, Warszawski L, Fontes R, Domingues RC, Gadelha MR: BMI and metabolic profile in patients with prolactinoma before and after treatment with dopamine agonists. Obesity (Silver Spring) 2011, 19:800-805.

30. Cincotta AH, Wilson JM, DeSouza CJ, Meier AH: Properly timed injections of cortisol and prolactin produce long-term reductions in obesity, hyperinsulinaemia and insulin resistance in the Syrian hamster (Mesocricetus auratus). J Endocrinol 1989, 120:385-391.

31. Cincotta AH, Schiller BC, Landry RJ, Herbert SJ, Miers WR, Meier AH: Circadian neuroendocrine role in age-related changes in body fat stores and insulin sensitivity of the male Sprague-Dawley rat. Chronobiol Int 1993, 10:244-258.

32. Park S, Kang S, Lee HW, Ko BS: Central prolactin modulates insulin sensitivity and insulin secretion in diabetic rats. Neuroendocrinology 2012, 95:332-343.

33. Cincotta $\mathrm{AH}$, Meier $\mathrm{AH}$ : Prolactin permits the expression of a circadian variation in lipogenic responsiveness to insulin in hepatocytes of the golden hamster (Mesocricetus auratus). J Endocrinol 1985, 106:173-176.

34. Cincotta $\mathrm{AH}$, Meier $\mathrm{AH}$ : Prolactin permits the expression of a circadian variation in insulin receptor profile in hepatocytes of the golden hamster (Mesocricetus auratus). J Endocrinol 1985, 106:177-181.

35. Cincotta $\mathrm{AH}$, Meier $\mathrm{AH}$ : Prolactin influences the circadian rhythm of lipogenesis in primary cultured hepatocytes. Horm Metab Res 1989, 21:64-68.

36. Spark RF, Dickstein G: Bromocriptine and endocrine disorders. Ann Intern Med 1979, 90:949-956.

37. Verhelst J, Abs R: Hyperprolactinemia: pathophysiology and management. Treat Endocrinol 2003, 2:23-32. 
38. Chen Y, Hong F, Chen H, Fan RF, Zhang XL, Zhang Y, Zhu JX: Distinctive expression and cellular distribution of dopamine receptors in the pancreatic islets of rats. Cell Tissue Res 2014, Epub ahead of print.

39. Rubí B, Ljubicic S, Pournourmohammadi S, Carobbio S, Armanet M, Bartley C, Maechler P: Dopamine D2-like receptors are expressed in pancreatic beta cells and mediate inhibition of insulin secretion. J Biol Chem 2005, 280:36824-36832.

40. Simpson N, Maffei A, Freeby M, Burroughs S, Freyberg Z, Javitch J, Leibel RL, Harris PE: Dopamine-mediated autocrine inhibitory circuit regulating human insulin secretion in vitro. Mol Endocrinol 2012, 26:1757-1772.

41. Ustione A, Piston DW, Harris PE: Minireview: Dopaminergic regulation of insulin secretion from the pancreatic islet. Mol Endocrinol 2013, 27:1198-1207.

42. Van Weenen JE DL, Parlevliet ET, Maechler P, Havekes LM, Romijn JA, Ouwens DM, Pijl H, Guigas B: The dopamine receptor D2 agonist bromocriptine inhibits glucose-stimulated insulin secretion by direct activation of the alpha2-adrenergic receptors in beta cells. Biochem Pharmacol 2010, 79:1827-1836

43. Cincotta $\mathrm{AH}$, Meier $\mathrm{AH}$ : Bromocriptine (Ergoset) reduces body weight and improves glucose tolerance in obese subjects. Diabetes Care 1996, 19:667-670.

44. Cincotta AH, Meier AH, Burritt $H$, Raskin P: Bromocriptine (Ergoset ${ }^{\mathrm{TM}}$ ) improves glycemic control in obese-NIDDM subjects [abstract]. Diabetes 1995, 44(Suppl 1):168A.

45. Bina KG, Cincotta AH: Dopaminergic agonists normalize elevated hypothalamic neuropeptide $Y$ and corticotropin-releasing hormone, body weight gain, and hyperglycemia in ob/ob mice. Neuroendocrinology 2000, 71:68-78.

46. Liang $Y$, Lubkin $M$, Sheng $H$, Scislowski PW, Cincotta AH: Dopamine agonist treatment ameliorates hyperglycemia, hyperlipidemia, and the elevated basal insulin release from islets of ob/ob mice. Biochim Biophys Acta 1998, 1405:1-13.

47. Liang $Y$, Jetton TL, Lubkin M, Meier AH, Cincotta AH: Bromocriptine/ SKF38393 ameliorates islet dysfunction in the diabetic (db/db) mouse. Cell Mol Life Sci 1998, 54:703-711.

48. Pacini G: The hyperbolic equilibrium between insulin sensitivity and secretion. Nutr Metab Cardiovasc Dis 2006, 16(Suppl 1):S22-S27.

49. Sun Z, Lazar MA: Dissociating fatty liver and diabetes. Trends Endocrinol Metab 2013, 24:4-12.

50. Begriche K, Igoudjil A, Pessayre D, Fromenty B: Mitochondrial dysfunction in NASH: causes, consequences and possible means to prevent it. Mitochondrion 2006, 6:1-28.

51. Begriche K, Massart J, Robin MA, Bonnet F, Fromenty B: Mitochondrial adaptations and dysfunctions in nonalcoholic fatty liver disease. Hepatology 2013, 58:1497-1507.

52. Gao D, Nong S, Huang X, Lu Y, Zhao H, Lin Y, Man Y, Wang S, Yang J, Li J: The effects of palmitate on hepatic insulin resistance are mediated by NADPH Oxidase 3-derived reactive oxygen species through JNK and p38MAPK pathways. J. Biol. Chem 2010, 285:29965-29973.

53. Hotamisligil GS: Inflammation and metabolic disorders. Nature 2006, 14:860-867.

54. Iozzo P, Bucci M, Roivainen A, Nagren K, Jarvisalo MJ, Kiss J, Guiducci L, Fielding B, Naum AG, Borra R, Virtanen K, Savunen T, Salvadori PA, Ferrannini E, Knuuti J, Nuutila P: Fatty acid metabolism in the liver, measured by positron emission tomography, is increased in obese individuals. Gastroenterology 2010, 139:846-856.

55. Nakamura S, Takamura T, Matsuzawa-Nagata N, Takayama H, Misu H, Noda H, Nabemoto S, Kurita S, Ota T, Ando H, Miyamoto K, Kaneko S: Palmitate induces insulin resistance in $\mathrm{H} 4 \mathrm{IIEC} 3$ hepatocytes through reactive oxygen species produced by mitochondria. J Biol Chem 2009, 284:14809-14818.

56. Satapati S, Sunny NE, Kucejova B, Fu X, He TT, Méndez-Lucas A, Shelton JM, Perales JC, Browning JD, Burgess SC: Elevated TCA cycle function in the pathology of diet-induced hepatic insulin resistance and fatty liver. J Lipid Res 2012, 53:1080-1092.

57. Sunny NE, Parks EJ, Browning JD, Burgess SC: Excessive hepatic mitochondrial TCA cycle and gluconeogenesis in humans with nonalchoholic fatty liver disease. Cell Metab 2011, 14:804-810.

58. Chan SM, Sun RQ, Zeng XY, Choong ZH, Wang H, Watt MJ, Ye JM: Activation of PPARa ameliorates hepatic insulin resistance and steatosis in high fructose-fed mice despite increased endoplasmic reticulum stress. Diabetes 2013, 62:2095-2105.
59. Cheng Z, Guo S, Copps K, Dong X, Kollipara R, Rodgers JT, Depinho RA, Puigserver $P$, White MF: Foxo1 integrates insulin signaling with mitochondrial function in the liver. Nat Med 2009, 15:1307-1311.

60. Huang J, Jia Y, Fu T, Viswakarma N, Bai L, Rao MS, Zhu Y, Borensztajn J, Reddy JK: Sustained activation of PPARa by endogenous ligands increases hepatic fatty acid oxidation and prevents obesity in ob/ob mice. FASEB J 2012, 26:628-638.

61. Hwang JH, Kim DW, Jo EJ, Kim YK, Jo YS, Park JH, Yoo SK, Park MK, Kwak TH, Kho YL, Han J, Choi HS, Lee SH, Kim JM, Lee I, Kyung T, Jang C, Chung J, Kweon GR, Shong M: Pharmacological stimulation of NADH oxidation ameliorates obesity and related phenotypes in mice. Diabetes 2009, 58:965-974.

62. Monsenego J, Mansouri A, Akkaoui M, Lenoir V, Esnous C, Fauveau V, Tavernier V, Girard J, Prip-Buus C: Enhancing liver mitochondrial fatty acid oxidation capacity in obese mice improves insulin sensitivity independently of hepatic steatosis. J Hepatol 2012, 56:632-639.

63. Orellana-Gavalda JM, Herrero L, Malandrino MI, Paneda A, Sol Rodriguez-Pena M, Petry H, Asins G, Van Deventer S, Hegardt FG, Serra D: Molecular therapy for obesity and diabetes based on a long-term increase in hepatic fattyacid oxidation. Hepatology 2011, 53:821-832.

64. Serra D, Mera P, Malandrino MI, Mir JF, Herrero L: Mitochondrial fatty acid oxidation in obesity. Antioxid Redox Signal 2013, 19:269-284.

65. Boden G, She P, Mozzoli M, Cheung P, Gumireddy K, Reddy P, Xiang X, Luo Z, Ruderman N: Free fatty acids produce insulin resistance and activate the proinflammatory nuclear factor-kB pathway in rat liver. Diabetes 2005, 54:3458-3465.

66. Galbo T, Olsen GS, Quistorff B, Nishimura E: Free fatty acid-induced PP2A hyperactivity selectively impairs hepatic insulin action on glucose metabolism. PLoS One 2011, 6:e27424.

67. Estall JL, Kahn M, Cooper MP, Fisher FM, Wu MK, Laznik D, Qu L, Cohen DE, Shulman Gl, Spiegelman BM: Sensitivity of lipid metabolism and insulin signaling to genetic alterations in hepatic peroxisome proliferator-activated receptor-gamma coactivator-1alpha expression. Diabetes 2009, 58:1499-1508.

68. Glick D, Zhang W, Beaton M, Marsboom G, Gruber M, Simon MC, Hart J, Dorn GW 2nd, Brady MJ, Macleod KF: BNip3 regulates mitochondrial function and lipid metabolism in the liver. Mol Cell Biol 2012, 32:2570-2584.

69. Kersten S, Seydoux J, Peters JM, Gonzalez FJ, Desvergne B, Wahli W: Peroxisome proliferator-activated receptor alpha mediates the adaptive response to fasting. J Clin Invest 1999, 103:1489-1498.

70. Koo SH, Satoh H, Herzig S, Lee CH, Hedrick S, Kulkarni R, Evans RM, Olefsky J, Montminy M: PGC-1 promotes insulin resistance in liver through PPAR-alpha-dependent induction of TRB-3. Nat Med 2004, 10:530-534.

71. Kulozik P, Jones A, Mattijssen F, Rose AJ, Reimann A, Strzoda D, Kleinsorg S, Raupp C, Kleinschmidt J, Müller-Decker K, Wahli W, Sticht C, Gretz N, Von Loeffelholz C, Stockmann M, Pfeiffer A, Stöhr S, Dallinga-Thie GM, Nawroth PP, Berriel Diaz M, Herzig S: Hepatic deficiency in transcriptional cofactor TBL1 promotes liver steatosis and hypertriglyceridemia. Cell Metab 2011 13:389-400

72. Leone TC, Lehman JJ, Finck BN, Schaeffer PJ, Wende AR, Boudina S, Courtois M, Wozniak DF, Sambandam N, Bernal-Mizrachi C, Chen Z, Holloszy JO, Medeiros DM, Schmidt RE, Saffitz JE, Abel ED, Semenkovich CF, Kelly DP: PGC-1alpha deficiency causes multi-system energy metabolic derangements: muscle dysfunction, abnormal weight control and hepatic steatosis. PLOS Biol 2005, 3:e101.

73. Nyman LR, Tian L, Hamm DA, Schoeb TR, Gower BA, Nagy TR, Wood PA: Long term effects of high fat or high carbohydrate diets on glucose tolerance in mice with heterozygous carnitine palmitoyltransferase-1a (CPT-1a) deficiency: Diet influences on CPT1a deficient mice. Nutr Diabetes 2011, 1:e14.

74. Daitoku H, Yamagata K, Matsuzaki H, Hatta M, Fukamizu A: Regulation of PGC-1 promoter activity by protein kinase $B$ and the forkhead transcription factor FKHR. Diabetes 2003, 52:642-649.

75. Monsénégo J, Mansouri A, Akkaoui M, Lenoir V, Esnous C, Fauveau V, Tavernier V, Girard J, Prip-Buus C: Enhancing liver mitochondrial fatty acid oxidation capacity in obese mice improves insulin sensitivity independently of hepatic steatosis. J Hepatology 2012, 54:632-639.

76. Nagle CA, Klett El, Coleman RA: Hepatic triacylglycerol accumulation and insulin resistance. J Lipid Res 2009, 50:S74-S79.

77. Samuel VT, Liu ZX, Qu X, Elder BD, Bilz S, Befroy D, Romanelli AJ, Shulman $\mathrm{Gl}$ : Mechanism of hepatic insulin resistance in non-alcoholic fatty liver disease. J Biol Chem 2004, 279:32345-32353. 
78. Muoio DM, Newgard CB: Fatty acid oxidation and insulin action: when less is more. Diabetes 2008, 57:1455-1456.

79. Pospisilik JA, Knauf C, Joza N, Benit P, Orthofer M, Cani PD, Ebersberger I, Nakashima T, Sarao R, Neely G, Esterbauer H, Kozlov A, Kahn CR, Kroemer G, Rustin P, Burcelin R, Penninger JM: Targeted deletion of AIF decreases mitochondrial oxidative phosphorylation and protects from obesity and diabetes. Cell 2007, 131:476-491.

80. Cai D, Yuan M, Frantz DF, Melendez PA, Hansen L, Lee J, Shoelson SE: Local and systemic insulin resistance resulting from hepatic activiation of IKK-B and NFkB. Nat Med 2005, 11:183-190.

81. Petersen KF, Shulman Gl: Etiology of insulin resistance. Am J Med 2006, 119(Suppl 1):S10-S16.

82. Vanni E, Abate ML, Gentilcore E, Hickman I, Gambino R, Cassader M, Smedile A, Ferrannini E, Rizzetto M, Marchesini G, Gastaldelli A, Bugianesi E: Sites and mechanisms of insulin resistance in nonobese, nondiabetic patients with chronic hepatitis C. Hepatology 2009, 50:697-706.

83. Hirosumi J, Tuncman G, Chang L, Görgün CZ, Uysal KT, Maeda K, Karin M, Hotamisligil GS: A central role for JNK in obesity and insulin resistance. Nature 2002, 420:333-336.

84. Lim JH, Lee $H J$, Jung MH, Song J: Coupling mitochondrial dysfunction to endoplasmic reticulum stress response: A molecular mechanism leading to hepatic insulin resistance. Cell Signal 2009, 21:169-177.

85. Kumashiro N, Tamura Y, Uchida T, Ogihara T, Fujitani Y, Hirose T, Mochizuki $H$, Kawamori R, Watada $H$ : Impact of oxidative stress and peroxisome proliferator-activated receptor gamma coactivator-1alpha in hepatic insulin resistance. Diabetes 2008, 57:2083-2091.

86. Barthel A, Schmoll D: Novel concepts in insulin regulation of hepatic gluconeogenesis. Am J Physiol Endocrinol Metab 2003, 285:E685-E692.

87. Lin J, Yang R, Tarr PT, Wu PH, Handschin C, Li S, Yang W, Pei L, Uldry M, Tontonoz P, Newgard CB, Spiegelman BM: Hyperlipidemic effects of dietary saturated fats mediated through PGC $-1 \beta$ coactivation of SREBP. Cell 2005, 120:261-273.

88. Morino K, Petersen KF, Shulman GI: Molecular mechanisms of insulin resistance in humans and their potential links with mitochondrial dysfunction. Diabetes 2010, 55:S9-S15.

89. Murphy MP: How mitochondria produce reactive oxygen species. Biochem J 2009, 417:1-13.

90. Finck BN, Kelly DP: PGC-1 coactivators: inducible regulators of energy metabolism in health and disease. J Clin Invest 2006, 116:615-622.

91. Herzig S, Long F, Jhala US, Hedrick S, Quinn R, Bauer A, Rudolph D, Schutz $G$, Yoon C, Puigserver P, Spiegelman B, Montminy M: CREB regulates hepatic gluconeogenesis through the coactivator PGC-1. Nature 2001, 413:179-183.

92. Miyake K, Ogawa W, Matsumoto M, Nakamura T, Sakaue H, Kasuga M: Hyperinsulinemia, glucose intolerance, and dyslipidemia induced by acute inhibition of phosphoinositide 3-kinase signaling in the liver. $J$ Clin Invest 2002, 110:1483-1491.

93. Puigserver $P$, Rhee J, Donovan J, Walkey CJ, Yoon JC, Oriente F, Kitamura Y, Altomonte J, Dong H, Accili D, Spiegelman BM: Insulin-regulated hepatic gluconeogenesis through FOXO1-PGC-1alpha interaction. Nature 2003, 423:550-555.

94. Rhee J, Inoue Y, Yoon JC, Puigserver P, Fan M, Gonzalez FJ, Spiegelman BM: Regulation of hepatic fasting response by PPARy coactivator-1a (PGC-1): requirement for hepatocyte nuclear factor $4 a$ in gluconeogenesis. Proc Natl Acad Sci U S A 2003, 100:4012-4017.

95. Yoon JC, Puigserver P, Chen G, Donovan J, Wu Z, Rhee J, Adelmant G, Stafford J, Kahn CR, Granner DK, Newgard CB, Spiegelman BM: Control of hepatic gluconeogenesis through the transcriptional coactivator PGC-1. Nature 2001, 413:131-138.

96. Zhang Y, Castellani LW, Sinal CJ, Gonzalez FJ, Edwards PA: Peroxisome proliferator-activated receptor- $\gamma$ coactivator $1 a(P G C-1 a)$ regulates triglyceride metabolism by activation of the nuclear receptor FXR. Genes Dev 2004, 18:157-169.

97. Zhou XY, Shibusawa N, Naik K, Porras D, Temple K, Ou H, Kaihara K, Roe MW, Brady MJ, Wondisford FE: Insulin regulation of hepatic gluconeogenesis through phosphorylation of CREB-binding protein. Nat Med 2004, 10:633-637.

98. Nakatani $Y$, Kaneto H, Kawamori D, Hatazaki M, Miyatsuka T, Matsuoka TA, Kajimoto Y, Matsuhisa M, Yamasaki Y, Hori M: Modulation of the JNK pathway in liver affects insulin resistance status. J Biol Chem 2004, 279:45803-45809.
99. Popa C, Riel PLCM, Meer WM, Stalenhoef AFH: The role of TNF-a in chronic inflammatory conditions, intermediary metabolism, and cardiovascular risk. J Lipid Res 2007, 48:751-762.

100. Torisu T, Sato N, Yoshiga D, Kobayashi T, Yoshioka T, Mori H, lida M, Yoshimura A: The dual function of hepatic SOCS3 in insulin resistance in vivo. Genes to Cells 2007, 12:143-154

101. Ueki K, Kondo T, Kahn CR: Central role of suppressors of cytokine signaling proteins in hepatic steatosis, insulin resistance, and the metabolic syndrome in the mouse. Proc Natl Acad Sci USA 2004, 101:10422-10427.

102. Nakae J, Kitamura T, Silver DL, Accili D: The forkhead transcription factor Foxo1 (Fkhr) confers insulin sensitivity onto glucose-6-phosphatase expression. J Clin Invest 2001, 108:1359-1367.

103. Gross DNA, van den Heuvel APJ, Birnbaum MJ: The role of FoxO in the regulation of metabolism. Oncogene 2008, 27:2320-2336.

104. Gross DN, Wan M, Birnbaum MJ: The role of FOXO in the regulation of metabolism. Curr Diabetes Rep 2009, 9:208-214.

105. Liang H, Balas B, Tantiwong P, Dube J, Goodpaster BH, O'Doherty RM, DeFronzo RA, Richardson A, Musi N, Ward WF: Whole body overexpression of PGC-1a has opposite effects on hepatic and muscle insulin sensitivity. Am J Physiol Endocrinol Metab 2009, 296:E945-E954.

106. van den Buuse M, Lambrechts AC: Bromocriptine-induced decrease in blood pressure in conscious spontaneously hypertensive rats: evidence for a peripheral site of action. J Pharm Pharmacol 1989, 41:644-646.

107. Nagai $Y$, Yonemitsu S, Erion DM, Iwasaki T, Stark R, Weismann D, Dong J, Zhang D, Jurczak MJ, Löffler MG, Cresswell J, Yu XX, Murray SF, Bhanot S, Monia BP, Bogan JS, Samuel V, Shulman Gl: The role of peroxisome proliferator-activated receptor gamma coactivator-1 beta in the pathogenesis of fructose-induced insulin resistance. Cell Metab 2009, 9:252-264.

108. Kim JY, Song EH, Lee HJ, Oh YK, Choi KH, Yu DY, Park SI, Seong JK, Kim WH: $\mathrm{HBx}$-induced hepatic steatosis and apoptosis are regulated by TNFR1- and NF-kappaB-dependent pathways. J Mol Biol 2010, 397:917-931.

109. Kim YM, Kim TH, Kim YW, Yang YM, Ryu Da H, Hwang SJ, Lee JR, Kim SC, Kim SG: Inhibition of liver $\mathrm{X}$ receptor- $\boldsymbol{a}$-dependent hepatic steatosis by isoliquiritigenin, a licorice antioxidant flavonoid, as mediated by JNK1 inhibition. Free Radic Biol Med 2010, 49:1722-1734.

110. Singh R, Wang Y, Xiang Y, Tanaka KE, Guarde WA, Czaja MJ: Differential effects of JNK1 and JNK2 inhibition on murine steatohepatitis and insulin resistance. Hepatology 2009, 49:87-96.

111. Musso G, Gambino R, Cassader M: Recent insights into hepatic lipid metabolism in non-alcoholic fatty liver disease (NAFLD). Prog Lipid Res 2009, 48:1-26.

112. Wang D, Wei Y, Pagliassotti MJ: Saturated fatty acids promote endoplasmic reticulum stress and liver injury in rats with hepatic steatosis. Endocrinology 2006, 147:943-951.

113. Werstuck GH, Lentz SR, Dayal S, Hossain GS, Sood SK, Shi YY, Zhou J, Maeda N, Krisans SK, Malinow MR, Austin RC: Homocysteine- induced endoplasmic reticulum stress causes dysregulation of the cholesterol and triglyceride biosynthetic pathways. J Clin Invest 2001, 107:1263-1273.

114. You M, Crabb DW: Molecular mechanisms of alcoholic fatty liver: role of sterol regulatory element-binding proteins. Alcohol 2004, 34:39-43.

115. Gavrilova O, Haluzik M, Matsusue K, Cutson JJ, Johnson L, Dietz KR, Nicol CJ, Vinson C, Gonzalez FJ, Reitman ML: Liver peroxisome proliferator activated receptor gamma contributes to hepatic steatosis, triglyceride clearance, and regulation of body fat mass. J Biol Chem 2003, 278:34268-34276.

116. Matsusue K, Haluzik M, Lambert G, Yim SH, Gavrilova O, Ward JM, Brewer B $\mathrm{Jr}$, Reitman ML, Gonzalez FJ: Liver-specific disruption of PPARgamma in leptin-deficient mice improves fatty liver but aggravates diabetic phenotypes. J Clin Invest 2003, 111:737-747.

117. Savage DB, Tan GD, Acerini CL, Jebb SA, Agostini M, Gurnell M, Williams RL, Umpleby AM, Thomas EL, Bell JD, Dixon AK, Dunne F, Boiani R, Cinti S, Vidal-Puig A, Karpe F, Chatterjee VK, O'Rahilly S: Human metabolic syndrome resulting from dominant-negative mutations in the nuclear receptor peroxisome proliferator-activated receptor-gamma. Diabetes 2003, 52:910-917.

118. Park HJ, Jung UJ, Cho SJ, Jung HK, Shim S, Choi MS: Citrus unshiu peel extract ameliorates hyperglycemia and hepatic steatosis by altering inflammation and hepatic glucose- and lipid-regulating enzymes in db/db mice. J Nutr Biochem 2013, 24:419-427. 
119. Kim JH, Kim JE, Liu HY, Cao W, Chen J: Regulation of interleukin-6-induced hepatic insulin resistance by mammalian target of rapamycin through the STAT3-SOCS3 pathway. J Biol Chem 2008, 283:708-715.

120. Liang Y, Cincotta AH: Increased responsiveness to the hyperglycemic, hyperglucagonemic and hyperinsulinemic effects of circulating norepinephrine in ob/ob mice. Int J Obes Relat Metab Disord 2001, 25:698-704

121. Aguilar E, Rodríguez-Padilla ML, Pinilla L: Normoprolactinaemia in spontaneously hypertensive rats: absence of a close relationship between plasma concentrations of prolactin and systolic blood pressure. J Endocrinol 1990, 125:359-364.

122. Hutchinson JS, Di Nicolantonio R, Lim A, Clements J, Funder JW: Effects of bromocriptine on blood pressure and plasma beta-endorphin in spontaneously hypertensive rats. Clin Sci (Lond) 1981, 61(Suppl 7):343s-345s.

123. Kanayama Y, Kohno M, Takaori K, Itoh S, Yasunari K, Takeda T: Involvement of sympathetic nervous system inhibition in the hypotensive effect of bromocriptine in spontaneously hypertensive rats. Clin Exp Pharmacol Physiol 1987, 14:141-144.

124. Oguro M, Takeda K, Itoh $\mathrm{H}$, Takesako T, Tanaka M, Takenaka K, Hirata M, Nakata T, Tanabe S, Hayashi J: Role of sympathetic nerve inhibition in the vasodepressor effect of bromocriptine in normotensive and hypertensive rats. Jpn Circ J 1992, 56:943-949.

125. Racz K, Kuchel O, Buu NT: Bromocriptine decreases blood pressure of spontaneously hypertensive rats without affecting the adrenomedullary synthesis of catecholamines. J Cardiovasc Pharmacol 1986, 8:676-680.

126. Struyker-Boudier HA, Van Essen H, Smits JF: Haemodynamic effects of bromocriptine in the conscious spontaneously hypertensive rat. J Pharm Pharmacol 1984, 36:123-125.

127. Tan BK, Hutchinson JS: Plasma and pituitary prolactin and blood pressure in bromocriptine-treated spontaneously hypertensive and Wistar-Kyoto rats. Clin Exp Pharmacol Physiol 1987, 14:797-803.

doi:10.1186/1758-5996-6-104

Cite this article as: Ezrokhi et al:: Neuroendocrine and metabolic components of dopamine agonist amelioration of metabolic syndrome in SHR rats. Diabetology \& Metabolic Syndrome 2014 6:104.

\section{Submit your next manuscript to BioMed Central and take full advantage of:}

- Convenient online submission

- Thorough peer review

- No space constraints or color figure charges

- Immediate publication on acceptance

- Inclusion in PubMed, CAS, Scopus and Google Scholar

- Research which is freely available for redistribution 